\title{
Effects of Improved Propulsion Modelling on the Flight Dynamics of Hypersonic Vehicles
}

\author{
Sean M. Torrez ${ }^{1 *}$, James F. Driscoll ${ }^{1 \dagger}$, Michael A. Bolender ${ }^{2} \ddagger$ \\ Michael W. Oppenheimer ${ }^{2}$, David B. Doman ${ }^{2}$ ฯ \\ ${ }^{1}$ Dept. of Aerospace Engineering, University of Michigan, Ann Arbor MI 48109 \\ ${ }^{2}$ Air Force Research Laboratory, Wright-Patterson AFB, OH 45433
}

Presented at the AIAA Atmospheric Flight Mechanics Conference, Honolulu, Hawaii, August 2008

\begin{abstract}
This research effort is focused on developing a control-oriented model of a generic hypersonic vehicle that includes the interactions between several integrated components. The present paper addresses the interactions between the propulsion system and the flight dynamics of the vehicle model for two different propulsion system models. The first model is a low-fidelity propulsion model that assumes the combustion process is Rayleigh flow, and the combustor is coupled with an isentropic diffuser and internal nozzle, thus ignoring the effects of internal shock waves, area variations, and real gas effects. A second, higherfidelity propulsion system model that includes several new phenomena then analyzed. This model includes a pre-combustion shock train within the isolator and its interactions with the combustor, the loss of stagnation pressure due to gas dissociation and recombination, wall heat transfer and skin friction, a fuel-air mixing submodel, and a finite-rate chemistry description of autoignition. When the new propulsion model is added, it is observed that the poles and zeros undergo a shift, with the short-period poles moving closer to the imaginary axis. The unstable transmission zeros associated with the flight path angle are also observed to move towards the imaginary axis, and take a much more pronounced shift as compared to the short-period poles. This is attributed to a reduced lift curve slope and pitch stiffness for the high fidelity propulsion system model that stems from an change in the thrust sensitivity to angle-of-attack.
\end{abstract}

\section{Introduction}

In recent years researchers at AFRL [1-4] have been developing a means of modelling a generic airbreathing hypersonic vehicle that is shown in the artist's concept in Figure 1. The purpose of these efforts has been to develop a modelling environment that can be used by both aircraft conceptual designers and flight dynamics and control engineers to help understand the physical manifestation of the complex interactions between the aerothermodynamics, propulsion system, control system, and structural dynamics that are expected to occur in full-scale scramjet-powered hypersonic vehicle configurations. Such a modelling environment will allow flight control engineers to obtain a fundamental understanding of the effects of these interactions on the open-loop dynamics of the system, and enable rapid exploration of the configuration design-space to enhance the controllability of the vehicle.

The philosophy of this research effort has been to incrementally add complexity to the model. This approach allows for each "improvement" to be assessed and to determine the impact that a particular new capability has on the flight dynamics of the vehicle. As can be expected, the model has undergone a rather

*Research Assistant, Student Member, AIAA

${ }^{\dagger}$ Professor of Aerospace Engineering, Fellow, AIAA

¥Aerospace Engineer, AFRL/RBCA, Senior Member AIAA.

$\S$ Electronics Engineer, AFRL/RBCA, Senior Member AIAA.

『Senior Aerospace Engineer, AFRL/RBCA, Associate Fellow AIAA. 
significant modification with regard to its fidelity. In Reference [4], viscous aerodynamic forces are added and the resulting shift in the poles and zeros is quantified. Reference [5] describes a new higher-fidelity propulsion model that was developed. It improves upon the original scramjet model, which was based on the Rayleigh flow approach and ignored the effects of internal shock waves, area variations, and real gas effects. This Rayleigh flow propulsion model now is being replaced with the higher-fidelity model [5] in order to account for several new phenomena: a pre-combustion shock train within the isolator and its interactions with the combustor, the loss of stagnation pressure due to gas dissociation and recombination, wall heat transfer and skin friction, a fuel-air mixing submodel, and a finite-rate chemistry and autoignition reaction mechanism.

The original version of the scramjet propulsion model used in References [1-4] was similar to ones developed by Chavez and Schmidt. ${ }^{6}$ The engine flow path is shown in Figure 2, and consists of a diffuser, a constant area combustor, and a nozzle. It was assumed that the diffuser and the nozzle were perfectly isentropic, and the combustion process was modelled as a change in total temperature, which in turn was a function of the equivalence ratio. This previous model used the pressure and temperature computed downstream of the oblique shock as the engine entrance boundary conditions. For a specified equivalence ratio, mass flow is calculated as a function of angle-of-attack and Mach number to determine the thrust. While this approach gives the correct qualitative thrust relationship as a function of Mach number, altitude, angle-of-attack, and equivalence ratio, in some parts of the flight envelope the combustor thermally chokes at very low equivalence ratios, which unrealistically limits the performance of the vehicle. Therefore, the motivation behind this paper is to better estimate the thrust and engine operability over a wider range of flight conditions, including ramjet to scramjet mode transition.

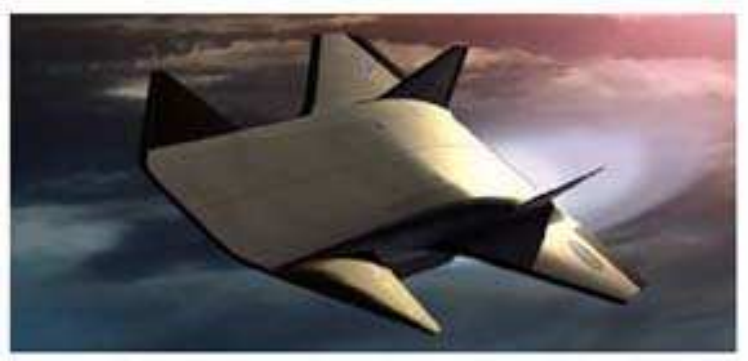

Figure 1. Artists Concept of a Generic Air-breathing Hypersonic Vehicle

\section{Generic Hypersonic Vehicle Model}

The hypersonic vehicle used in this analysis is based on a photographically scaled X-43A outer mold line, and only considers the longitudinal dynamics of the vehicle. This particular vehicle was chosen because its configuration is typical of a hypersonic cruise vehicle with an outward-turning, two-dimensional inlet. Vehicles of this type have a tightly integrated airframe and scramjet propulsion system, which is necessitated to ensure the scramjet performance is optimal. The vehicle is designed such that the forward fuselage of the aircraft creates a bow shock that acts as an external compression system for the scramjet engine. Typically, there are several compression ramps that serve to optimize the pressure, temperature, and mass flow at the engine inlet. The pressure distribution on the forebody also has a significant affect on the vehicle's stability and control characteristics due to the lift and nose-up pitching moment that it produces.

Downstream of the scramjet engine, the aft fuselage acts as half of an external nozzle for the exhaust gases, with a slip line formed by the interaction of the exhaust flow and the freestream forming the other half. The pressure acting on the aftbody due to the expansion of the exhaust is a function of the pressure of the exhaust gas as it exits the scramjet engine. The pressure produced by the expanding exhaust flow contributes to the lift of the vehicle, partially offsets the drag, and produces a pitching moment that is stabilizing. With the engine below the center-of-gravity, the thrust produces a nose-up pitching moment that must be balanced by the elevator.

The structural modes for this class of vehicle also play an important role. As the structure vibrates, the bending of the fuselage effectively changes the outer mold line of the vehicle, resulting in slightly altered pressure distribution on the vehicle. The resulting changes in the pressure distribution over the aircraft 
are realized downstream as thrust, lift, drag, and pitching moment perturbations. The structural dynamics of the fuselage are modelled as the transverse vibrations of a free-free beam with a non-uniform mass and stiffness distribution. The stiffness distribution is assumed to vary with temperature in order to account for the effects of aerodynamic heating on the structural frequencies. The detailed analysis of flexibility effects is contained in Williams ${ }^{7}$ and Culler $^{8}$ and is not repeated here.

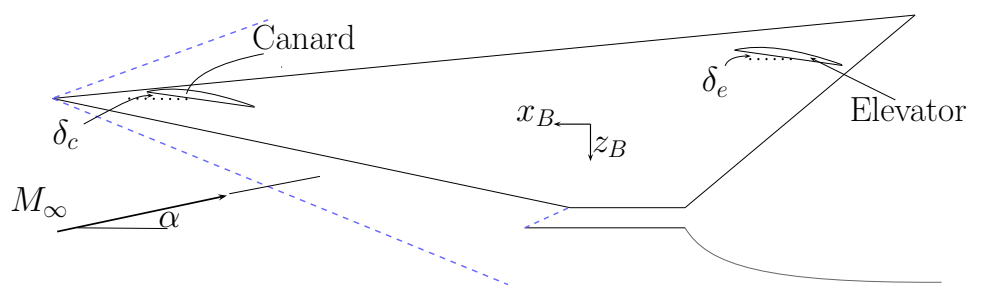

Figure 2. Hypersonic Air-breathing Vehicle Geometry

A schematic of the vehicle geometry that was chosen for this work is shown in Fig. 2. The aircraft can be configured with two aerodynamic control inputs: an elevator and canard. The thrust is controlled through the fuel equivalence ratio (fuel-to-air ratio normalized by the stoichiometric fuel-to-air ratio). It is assumed that the vehicle shown has unity depth into the paper.

\section{A. Aerodynamic Modelling}

The pressure on the forebody is determined by either oblique shock theory or Prandtl-Meyer flow and is dependent upon the combined effect of the angle-of-attack and the structural deflection at the nose of the vehicle along with the freestream Mach number.

For the case where there is an oblique shock, the shock angle with respect to the horizontal (in this case taken to be the direction of the oncoming freestream flow), is calculated by solving the following polynomial for $\sin ^{2} \theta_{s}$ (see Reference [9])

$$
\begin{aligned}
\sin ^{6} \theta_{s} & +b \sin ^{4} \theta_{s}+c \sin ^{2} \theta_{s}+d=0 \\
b & =-\frac{M_{\infty}^{2}+2}{M_{\infty}^{2}}-\gamma \sin ^{2} \delta \\
c & =\frac{2 M_{\infty}^{2}+1}{M_{\infty}^{4}}+\left[\frac{(\gamma+1)^{2}}{4}+\frac{\gamma-1}{M_{\infty}^{2}}\right] \sin ^{2} \delta \\
d & =-\frac{\cos ^{2} \delta}{M_{\infty}^{4}}
\end{aligned}
$$

The angle of the oblique shock is given by the second root of Equation (1a) as this particular wave angle corresponds to the weak shock solution.

Once the shock angle is determined, the pressure, temperature, and Mach number behind the oblique shock can be determined from the following relations: ${ }^{9}$

$$
\begin{aligned}
\frac{p_{1}}{p_{\infty}} & =\frac{7 M_{\infty}^{2} \sin ^{2} \theta_{s}-1}{6} \\
\frac{T_{1}}{T_{\infty}} & =\frac{\left(7 M_{\infty}^{2} \sin ^{2} \theta_{s}-1\right)\left(M_{\infty}^{2} \sin ^{2} \theta_{s}+5\right)}{36 M_{\infty}^{2} \sin ^{2} \theta_{s}} \\
M_{1}^{2} \sin ^{2}\left(\theta_{s}-\delta\right) & =\frac{M_{\infty}^{2} \sin ^{2} \theta_{s}+5}{7 M_{\infty}^{2} \sin ^{2} \theta_{s}-1}
\end{aligned}
$$

On the other hand, in the cases where there is flow over a convex corner, we will have a Prandtl-Meyer expansion. ${ }^{10}$ The process for calculating the new Mach number after the expansion requires that one first 
determine the angle $\nu_{1}$, which is the angle through which the flow expands from Mach 1 to the freestream Mach.

$$
\nu_{1}=\sqrt{\frac{\gamma+1}{\gamma-1}} \tan ^{-1} \sqrt{\frac{\gamma-1}{\gamma+1}\left(M_{\infty}^{2}-1\right)}-\tan ^{-1} \sqrt{M_{\infty}^{2}-1}
$$

To determine the resulting Mach number after the expansion, $M_{1}$, the following equation must be solved numerically:

$$
f\left(M_{1}\right)=\sqrt{\frac{\gamma+1}{\gamma-1}} \tan ^{-1} \sqrt{\frac{\gamma-1}{\gamma+1}\left(M_{1}^{2}-1\right)}-\tan ^{-1} \sqrt{M_{1}^{2}-1}-\nu_{2}
$$

where $\nu_{2}=\nu_{1}+\delta$ where $\delta$ is the angle through which the flow is turned. Once the solution to Equation (6) is determined, the flow properties after the expansion are found from the thermodynamic relations for isentropic flow: ${ }^{9}$

$$
\begin{aligned}
\frac{p_{1}}{p_{\infty}} & =\left[\frac{1+\frac{\gamma-1}{2} M_{\infty}^{2}}{1+\frac{\gamma-1}{2} M_{1}^{2}}\right]^{\frac{\gamma}{\gamma-1}} \\
\frac{T_{1}}{T_{\infty}} & =\left[\frac{1+\frac{\gamma-1}{2} M_{\infty}^{2}}{1+\frac{\gamma-1}{2} M_{1}^{2}}\right]
\end{aligned}
$$

Once the downstream pressures are calculated according to either Oblique Shock Theory or PrandtlMeyer Expansion Flow Theory, we determine the aerodynamic forces acting on the vehicle by integrating the pressures and resolving the corresponding forces and moments about the center-of-gravity into the appropriate coordinate frame.

\section{Piston Theory}

The aerodynamic model uses Linear Piston Theory to compute the unsteady pressure distribution on the vehicle that results from both flow-structure interaction and the unsteady, rigid body motion of the vehicle. Piston Theory has been used extensively by aeroelasticians to determine the pressure distributions on a flexible airfoil when the Mach number is sufficiently high. Lighthill ${ }^{11}$ first discussed the application of piston theory on oscillating airfoils some 50 years ago. Ashley and Zartarian ${ }^{12}$ discuss piston theory while providing a number of examples of the application of piston theory to specific problems. More recently, Tarpley ${ }^{13}$ discussed the computation of stability derivatives for a caret-wing waverider using Piston Theory, which requires the analysis of unsteady flow over the vehicle. ${ }^{13}$ Piston theory allows the inclusion of unsteady aerodynamic effects in the model and a closed form solution can be found for these unsteady effects.

Linear Piston Theory states that the pressure acting on the face of a piston moving in a perfect gas when the Mach number is greater than unity is: ${ }^{12}$

$$
\frac{P}{P_{i}}=\left(1+\frac{1}{5} \frac{V_{n, i}}{a_{i}}\right)^{7}
$$

where $P$ is the pressure on the piston face, $P_{i}$ is the local static pressure (i.e., behind the shock in the case of supersonic flow), $a_{i}$ is the local speed of sound, and $V_{n, i}$ is the velocity of the surface normal to the steady flow. Taking the binomial series of Equation 9 to first order gives

$$
\frac{P}{P_{i}}=1+\frac{7}{5} \frac{v_{n, i}}{a_{i}}
$$

Multiplying through by $P_{i}$, using the perfect gas law, and the definition for speed of sound gives the basic result from first-order linear piston theory:

$$
P=P_{i}+\rho_{i} a_{i} v_{n, i}
$$

where $\rho_{i}$ is the local density of the fluid. The normal velocity, $v_{n, i}$ is now a perturbation to the velocity $V_{n, i}$, and arises due to either the flexing of the aircraft, the aircraft's rotational motion, or a change in angle-of-attack from $V_{n, i}$.

The infinitesimal force acting on the face of the piston is

$$
d \boldsymbol{F}_{i}=-(P d A) \boldsymbol{n}_{i}
$$


In Equation 12, $\boldsymbol{n}$ is the outward pointing normal unit vector to the surface, $d A$ is the infinitesimal surface area, and $d \boldsymbol{F}_{i}$ is the incremental force. Substituting Equation 11 into Equation 12 gives

$$
d \boldsymbol{F}_{i}=\left[-\left(P_{i}+\rho_{i} a_{i} v_{n, i}\right) d A\right] \boldsymbol{n}_{i}
$$

However, since $v_{n, i}$ is by definition the perturbation velocity normal to the surface, we can write $v_{n, i}=\boldsymbol{v} \cdot \boldsymbol{n}_{i}$ where $\boldsymbol{v}$ is the perturbation velocity vector of the vehicle. Thus, the infinitesimal force becomes

$$
\left.d \boldsymbol{F}=-\left\{\left[P_{i}+\rho_{i} a_{i}\left(\boldsymbol{v} \cdot \boldsymbol{n}_{i}\right)\right] d A\right]\right\} \boldsymbol{n}_{i}
$$

Equation 14 is then integrated over each surface that defines the vehicle outer mold line to give the total force acting on the vehicle. From Equation 14 it should be noted that when $\int P_{i} d A \boldsymbol{n}_{i}$ is evaluated over the vehicle, this contribution will give exactly the quasi-static pressure distribution that is calculated in Reference [1]. The unsteady contribution comes from the normal component of the velocity for a given surface, $\boldsymbol{v}_{n} \cdot \boldsymbol{n}$. It is the unsteady contribution that will give rise to the damping derivatives, $M_{q}$, for example, and for lack of a better term, the structural damping derivatives, $M_{\dot{\eta}}$, etc. A thorough treatise on modelling the unsteady aerodynamics with piston theory for our generic vehicle is given in Oppenheimer. ${ }^{3}$

\section{Viscous Effects}

The integration of the pressure distribution on the vehicle will only gives us the pressure drag. However, one of the primary sources of drag is due to viscous friction of the fluid moving relative to the vehicle. The skin friction drag is proportional to the shear stress of the fluid acting at the vehicle. The local skin friction coefficient is defined as

$$
c_{f}=\frac{\tau_{w}}{(1 / 2) \rho_{\infty} V_{\infty}^{2}}
$$

where $\tau_{w}$ is the shear stress at the wall and $\rho_{\infty}$ and $V_{\infty}$ are the freestream density and velocity respectively. The local shear stress at the wall can be expressed as ${ }^{14}$

$$
\tau_{w}=\left.\mu \frac{\partial u}{\partial y}\right|_{w}
$$

where $\mu$ is the viscosity of the fluid, and $\partial u / \partial y$ is the velocity gradient through the boundary layer.

To calculate the drag, we will calculate the skin friction drag for each wetted surface on the vehicle. For our purposes we will assume that the boundary layer will be turbulent over the entire vehicle. This assumption is made to impart conservativeness in our skin friction drag calculation. Furthermore boundary layer transition is not well understood, even for flow over a flat plate, and therefore it is difficult to predict the transition from laminar to turbulent flow. We will employ a method attributed to Eckert that utilizes the concept of a reference temperature that takes into account the wall temperature.

The skin friction coefficient for turbulent, supersonic flow over a flat plate is given by: ${ }^{14}$

$$
c_{f}=\frac{0.0592}{\left(R e^{*}\right)^{1 / 5}}
$$

where $R e^{*}$ is the Reynolds number $(\rho V L / \mu)$ evaluated at a reference temperature. The reference temperature, $T^{*}$ is determined by

$$
T^{*}=T_{e}\left[1+M_{e}^{2}+0.58\left(\frac{T_{w}}{T_{e}}-1\right)\right]
$$

In Equation 18, $M_{e}$ is the Mach number at the edge the boundary layer, $T_{e}$ is the temperature at the edge of the boundary layer, $T_{w}$ is the wall temperature. From Reference [15], the steady-state wall temperature was assumed to be $2500^{\circ} \mathrm{R}$. Once the reference temperature $T^{*}$ is known, the density at the reference temperature is found from the perfect gas law using the static pressure of the fluid

$$
\rho^{*}=\frac{p}{R T^{*}}
$$

The viscosity at the reference temperature, $\mu^{*}$ is then calculated using Sutherland's Formula ${ }^{9}$

$$
\mu^{*}=2.27 \times 10^{-8} \frac{\left(T^{*}\right)^{3 / 2}}{T^{*}+198.6}
$$


Sutherland's Formula is valid to approximately $3400^{\circ} \mathrm{R}$.

Once the reference Reynolds number has been calculated, the local skin friction coefficient can be calculated at any point along the vehicle. To determine the skin friction drag, we solve Equation 15 for $\tau_{w}$ and integrate over the each surface of the vehicle using the appropriate flow conditions. Further development of the viscous forces is given in Reference 4.

\section{Propulsion System Modelling}

\section{A. Simplified Propulsion Model}

The original model of the scramjet propulsion system ${ }^{1}$ was identical to that of Chavez and Schmidt, ${ }^{6}$ while the new propulsion model ${ }^{5}$ includes analysis to account for the fuel-air mixing of a jet in a cross flow, finite rate kinetics of combustion, dissociation and recombination, and combustor-isolator interactions that determine the strength of the pre-combustion shock train. The geometry of the engine flowpath is given in Figure 3 .

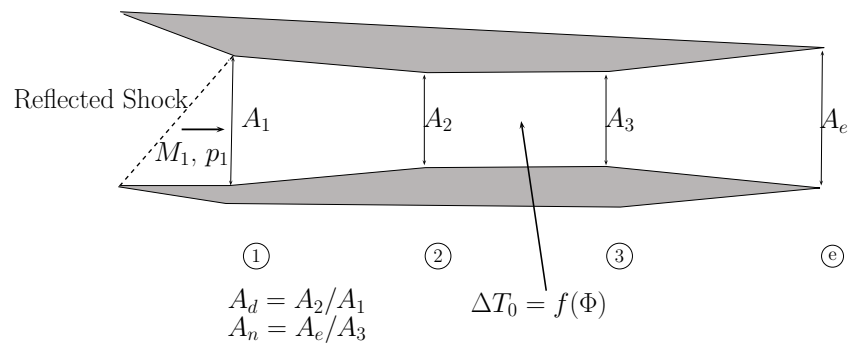

Figure 3. Scramjet Engine Flowpath

The conditions given at the engine inlet (station 1) are primarily determined by the Mach number and angle-of-attack at which the aircraft is flying, which are the parameters that determine the properties of flow downstream of the bow shock. The flow through the diffuser is assumed to be isentropic (i.e., without loss). The control variable that determines the thrust setting is the fuel equivalence ratio. The equivalence ratio effectively determines the change in total temperature that results from the combustion process. Choosing the stagnation temperature increase as a control parameter is the same as controlling the fuel flow, because we can determine from the flight condition (Mach and angle-of-attack) the mass flow that is captured by the propulsion system. This avoids having to make a priori assumptions regarding the fuel schedule and the parameters used for scheduling. Because the air entering the combustor is supersonic, the heat release due to fuel combustion reduces the Mach number of the airstream that is passing through the engine. Therefore, the amount of heat added due to the combustion process must be regulated to ensure that the combustor flow does not become thermally choked.

The flow encounters an oblique shock at the nose of the vehicle. Upon encountering the cowl, an expansion forms at the top of the duct, while an oblique shock forms at the bottom of the duct. These waves interact as the flow proceeds downstream. To reduce complexity, no interaction was considered, but rather an expansion fan and oblique shock were considered in sequence, which is a computationally cheap solution. This approach yields conditions inside the duct that only differ from the expected mass flow (which is calculated by area ratio) by $3.4 \%$.

In the diffuser, we apply the continuity equation (conservation of mass) to determine the Mach number at the diffuser exit/combustor inlet (station 2) given the diffuser inlet Mach:

$$
\frac{\left[1+\frac{\gamma-1}{2} M_{2}^{2}\right]^{\frac{\gamma+1}{\gamma-1}}}{M_{2}^{2}}=A_{d}^{2} \frac{\left[1+\frac{\gamma-1}{2} M_{1}^{2}\right]^{\frac{\gamma+1}{\gamma-1}}}{M_{1}^{2}}
$$

If an additional control variable is desired, $A_{d}$ can be made variable. Previously, $A_{d}$ was held constant at unity. However, it was found that upon inclusion of finite-rate chemistry, this area ratio did not cause sufficient contraction of the flow to raise the pressure and temperature of the flow to the point where 
combustion was possible. The same contraction ratio $\left(A_{d}=0.1\right)$ are used in both the old and new combustion models. The pressure and temperature at station 2 are determined by Equations (7) and (8).

The combustor is modelled as a constant-area, frictionless duct with heat addition. The Mach number at the combustor exit (station 3) is given by

$$
\frac{M_{3}^{2}\left[1+\frac{1}{2}(\gamma-1) M_{3}^{2}\right]}{\left(\gamma M_{3}^{2}+1\right)^{2}}=\frac{M_{2}^{2}\left(1+\frac{1}{2}[\gamma-1) M_{2}^{2}\right]}{\left(\gamma M_{2}^{2}+1\right)^{2}}+\frac{M_{2}^{2}}{\left(\gamma M_{2}^{2}+1\right)^{2}} \frac{\Delta T_{c}}{T_{2}}
$$

The pressure and temperature at the combustor exit are

$$
\begin{aligned}
& p_{3}=p_{2} \frac{1+\gamma M_{2}^{2}}{1+\gamma M_{3}^{2}} \\
& T_{3}=\frac{M_{3}^{2}}{M_{2}^{2}} \frac{\left(1+\gamma M_{2}^{2}\right)^{2}}{\left(1+\gamma M_{1}^{2}\right)^{2}}
\end{aligned}
$$

Conservation of enthalpy leads to the following relation for the ratio of total temperature at the combustor exit to the total temperature at the combustor inlet:

$$
\frac{T_{t 3}}{T_{t 2}}=\frac{1+\frac{H_{f} \eta_{c} f_{s t} \Phi}{c_{p} T_{t 2}}}{1+f_{s t} \Phi}
$$

The flow, upon leaving the combustor, enters a diverging, isentropic nozzle that will ultimately increase the exit Mach number. The exit nozzle area ratio is assumed to be fixed. The exit Mach number is given by:

$$
\frac{\left(1+\frac{\gamma-1}{2} M_{e}^{2}\right)^{\frac{\gamma+1}{\gamma-1}}}{M_{2}^{e}}=A_{n}^{2} \frac{\left(1+\frac{\gamma-1}{2} M_{3}^{2}\right)^{\frac{\gamma+1}{\gamma-1}}}{M_{3}^{2}}
$$

The thrust is calculated by applying the momentum theorem from fluid mechanics to a control volume that encloses the scramjet engine. The thrust is given by:

$$
\mathcal{T}=\dot{m}_{a}\left(V_{e}-V_{\infty}\right)+\left(p_{e}-p_{\infty}\right) A_{e}-\left(p_{1}-p_{\infty}\right) A_{i}
$$

An important parameter in the above thrust equation is the mass flow of air. The amount of mass flow captured by the engine inlet is a function of the shock angle. Typically, the aircraft geometry is designed such that the bow shock impinges upon the engine inlet lip at the design cruise condition. This will result in maximum mass flow through the engine module. At off design conditions, where the bow shock no longer impinges on the lip (cruise Mach less than the design Mach at the same angle of attack), there will be mass flow spillage, as the shock will be positioned in front of the cowl lip.

The pressure acting on the aftbody of the vehicle is due to the external expansion of the exhaust from the scramjet engine. The aftbody forms the upper part of a nozzle, whereas the shear layer that results from the interaction of the exhaust plume with the freestream flow forms the lower surface. The pressure distribution along the aftbody is then a function of the position of the shear layer. The shear layer is formed where the pressure in the plume is balanced by the freestream pressure. A reasonable approximation for the pressure at any point on the aftbody is given by Chavez and Schmidt: ${ }^{6}$

$$
p_{a}=\frac{p_{e}}{1+\frac{s_{a}}{L_{a}}\left(\frac{p_{e}}{p_{\infty}}-1\right)}
$$

The aftbody pressure makes a contribution to the lift and also acts to offset the drag of the forebody.

\section{B. Improved, Higher-Fidelity Propulsion Model}

The new model consists of a set of ordinary differential equations that govern the heat addition to a variable area duct, which are derived by Shapiro. ${ }^{16}$ More recently, O'Brien, Starkey, and Lewis ${ }^{17}$ Starkey, ${ }^{18}$ Birzer and Doolan, ${ }^{19}$ and Tetlow and Doolan ${ }^{20}$ have constructed propulsion system models of varying fidelity to support hypersonic vehicle design studies. The present work extends the previous models by including precombustor shock train, fuel mixing and finite-rate chemistry. 
The mixing model is based on recent experiments of jets mixing in supersonic cross flows. The 18 step finite-rate chemistry mechanism of Zambon and Chelliah ${ }^{21}$ was added to account for the use of either ethylene, hydrogen or methane fuel. The finite-rate chemistry mechanism has been carefully validated in Reference [21] for high temperature reactants that are in the autoignition regime. Gas dissociation and variable heat capacity are included to model the stagnation temperature loss that occurs due to dissociation. Some of this loss can be recovered in the nozzle provided that there is sufficient time for recombination. Wall heat transfer and skin friction effects also are included. This paper is divided into five sections that describe the combustion process: fuel-air mixing, chemical kinetics, the combustor-isolator interaction ${ }^{22}$ and dissociation across shock waves. ${ }^{14}$ In the section on the combustor-isolator interaction, a method is described to compute stagnation pressure losses across the pre-combustor shock train in the isolator.

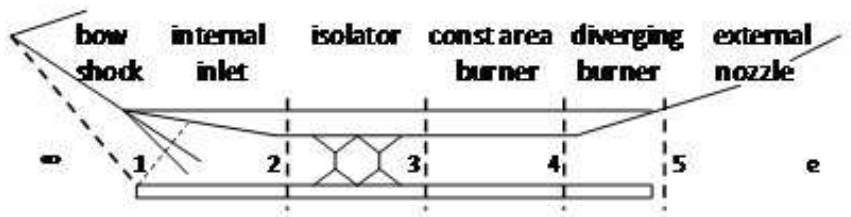

Figure 4. Schematic of Dual-Mode Scramjet Engine

The combustor section shown in Figure 4 consists of two parts: a nearly constant area burner (3-4) into which the mass flow rate of fuel injected is $\dot{m}_{f, 34}$ followed by a diverging area burner (4-5) into which the fuel injected is $\dot{m}_{f, 45}$. For reasons described in Reference [23], during ramjet operation fuel must be injected into both burners, while for scramjet operation no fuel is injected into the diverging burner. The 1-D model of the combustor is based on the following well-established conservation equations:

$$
\begin{aligned}
\frac{1}{\rho} \frac{d \rho}{d x} & =\frac{1}{\dot{m}} \frac{d \dot{m}}{d x}-\frac{1}{U} \frac{d U}{d x}-\frac{1}{A} \frac{d A}{d x} \\
\frac{1}{U} \frac{d U}{d x} & =\frac{-1}{\gamma M^{2}}\left(\frac{1}{p} \frac{d p}{d x}+\frac{2 \gamma M^{2} C_{f}}{\mathcal{D}}+\frac{\gamma M^{2}(1-\epsilon)}{\dot{m}} \frac{d \dot{m}}{d x}\right) \\
\frac{1}{p} \frac{d p}{d x} & =\frac{1}{\rho} \frac{d \rho}{d x}+\frac{1}{T} \frac{d T}{d x}-\frac{1}{\overline{M W}} \frac{d \overline{M W}}{d x} \\
\frac{d \overline{M W}}{d x} & =-\overline{M W^{2}} \sum_{i}\left(\frac{1}{M W_{i}} \frac{d Y_{i}}{d x}\right) \\
\frac{d \dot{m}}{d x} & =\sum_{i} \frac{d \dot{m}_{i, a d d e d}}{d x} \\
\frac{d T}{d x} & =\frac{1}{\hat{c}_{p}}\left\{-\sum_{i}\left(h_{i} \frac{d Y_{i}}{d x}\right)+\left[\frac{1}{\dot{m}} \sum_{i} h_{i}\left(\frac{d \dot{m}_{i, a d d e d}}{d x}\right)-\frac{h_{0}}{\dot{m}} \frac{d \dot{m}}{d x}\right]-\frac{2 C_{f} c_{p}\left(T_{a w}-T_{w}\right)}{\operatorname{Pr}^{2 / 3} A}-U \frac{d U}{d x}\right\} \\
\frac{d Y_{i}}{d x} & =\frac{\dot{\omega}_{i} M W_{i} A}{\dot{m}}+\frac{1}{\dot{m}} \frac{d \dot{m}_{i, a d d e d}}{d x}-\frac{Y_{i}}{\dot{m}} \frac{d \dot{m}}{d x} \\
\dot{\omega}_{i} & =\frac{d C_{Q_{i}}}{d t}=\sum_{j}\left[k_{f, j}\left(\nu_{i j}^{\prime \prime}-\nu_{i j}^{\prime}\right) \prod_{i} C_{i}^{\nu_{i j}^{\prime}}\right]
\end{aligned}
$$

Equations 29-31, 35 and 36 represent the conservation of mass, momentum, energy, mass fraction $\left(Y_{i}\right)$ of the $i^{t h}$ species, and an equation of state $[16,17]$. They are written in the manner that is consistent with O'Brien et al. [17]. Equation 32 defines the molecular weight of the mixture, and Equation 36 defines $\omega_{i}$, which is volumetric reaction rate of the $i^{t h}$ species (in moles $/$ second $/ \mathrm{m}^{3}$ ). The right side of Equation 33 contains the mass per second of fluid added through the sidewalls; for all cases considered this added mass is the fuel.

Equations 29-36 represent $(6+2 N)$ equations for the $(6+2 N)$ unknowns $\left(\rho, U, p, \overline{M W}, T, \dot{m}, Y_{i}\right.$ and $\left.\dot{\omega}_{i}\right) . \quad N=22$ is the number of species in the reacting gas mixture. These equations contain a number of terms that are now described. First, consider the energy equation for the specific case when no fuel mass is 
added through the sidewalls $\left(\dot{m}_{i, \text { added }}=0\right)$. References [16] and [17] explain that the energy equation is:

$$
\frac{d h_{0}}{d x}=-\frac{2 C_{f} c_{p}\left(T_{a w}-T_{w}\right)}{\operatorname{Pr}^{2 / 3} A}
$$

The heat transfer coefficient $\left(C_{H}\right)$ does not appear because the heat loss to the wall instead is written in terms of the skin friction coefficient $C_{f}$, which is proportional to $C_{H}$ from the Reynolds analogy:

$$
C_{H}=\frac{C_{f}}{2 P r^{2 / 3}}
$$

The following equations define the stagnation enthalpy/mass $\left(h_{0}\right)$, the static enthalpy/mass $(h)$ and the static enthalpy/mass of the $i^{\text {th }}$ species $\left(h_{i}\right)$.

$$
\begin{aligned}
h & =\sum_{i} h_{i} Y_{i} \\
h_{0} & =h+\frac{1}{2} U^{2} \\
h_{i} & =h_{f, i}^{2}+\int_{298 K}^{T} c_{p, i} d T
\end{aligned}
$$

The heat of formation of the $i^{t h}$ species is $h_{f, i}^{0}$. Inserting Equations 39-41 into Equation 37, the left side of Equation 37 becomes:

$$
\begin{aligned}
\frac{d h_{0}}{d x} & =\sum_{i} Y_{i} \frac{d h_{i}}{d x}+\sum_{i} h_{i} \frac{d Y_{i}}{d x}+U \frac{d U}{d x} \\
& =\sum_{i}\left(Y_{i} c_{p, i}\right) \frac{d T}{d x}+\sum_{i} h_{i} \frac{d Y_{i}}{d x}+U \frac{d U}{d x} \\
& =c_{p} \frac{d T}{d x}+\sum_{i} h_{i} \frac{d Y_{i}}{d x}+U \frac{d U}{d x}
\end{aligned}
$$

The heat capacity of the gas mixture (which consists of 22 species) is defined as:

$$
c_{p}=\sum_{i} c_{p, i} Y_{i}
$$

It is seen that the final energy equation (34) is obtained by equating Equations 37 and 42 for the specific case of no mass addition. The heat that is liberated by combustion is determined by the values of the heat of formation $\left(h_{f, i}^{0}\right)$ terms in Equation 41. Similarly, when the gas dissociates (or recombines), these same heat of formation terms properly create the correct change in the stagnation temperature. When fuel mass is added through the sidewalls the two additional terms in the square brackets in Equation 34 must be included, as explained by the derivation found in Reference [17]. Note that these two terms in square brackets in Equation 34 sum to zero if the enthalpy/mass added by the fuel equals the enthalpy/mass of the main gas mixture, as expected. When fuel mass is added, Reference [17] shows that the effective heat capacity of the gas mixture is slightly modified, such that the quantity:

$$
\hat{c}_{p}=c_{p}-\frac{1}{\dot{m}} \sum_{i} c_{p, i} \dot{m}_{i, \text { added }}
$$

appears on the right side of Equation 34. The second term on the right side of Equation 44 is only a minor modification to the heat capacity, since the added mass flow rate is typically less than $3 \%$ of the total mass flow rate. The Mach number $\mathrm{M}$ in Equation 30 is defined as $U / \sqrt{\gamma R T}$, and the gas constant $R=R_{u} / \overline{M W}$, where $R_{u}$ is the universal gas constant. The quantities that must be provided to the model (as a function of the downstream coordinate $\mathrm{x}$ ) include:

1. the flow area $(A)$

2. the mass of the $i^{\text {th }}$ fuel species that is added $\left(\dot{m}_{i, \text { added }}\right)$, from the mixing submodel 
3. the reaction rate of the $i^{\text {th }}$ species $\left(\dot{\omega}_{i}\right)$, from the chemical kinetics submodel

4. the wall skin friction coefficient $\left(C_{f}\right)$

5. the hydraulic diameter $(\mathcal{D})$, which is defined to be $\left(\frac{4 A}{P_{w}}\right), P_{w}$ being the wetted perimeter of the duct

6. The parameter $(\epsilon)$ is either unity or zero if the mass added is in the direction of the flow or is perpendicular to the flow, respectively.

\section{Model of the Fuel-Air Mixing}

Fuel-air mixing is an important process that affects the engine thrust; the thrust is reduced if not all of the fuel mixes in the short time that fluid elements remain in the combustor. Fuel-air mixing is characterized by the term $\left(d \dot{m} / d x_{i}\right)_{a d d e d}$ that appears on the right side of Equation 33 . The quantity $\dot{m}_{i}$ in this term is the added mass/second of fuel that is molecularly mixed with the air; it is not simply the mass/second of fuel that enters the air stream. Fuel begins to become molecularly mixed at the fuel injection port, but molecularly-mixed fuel continues to be added to the air for a distance $L_{m}$ downstream of the fuel injection port. $L_{m}$ is defined to be the mixing distance required to mix the fuel and air to the rich flammability limit. After this mixing is completed, the second step in the combustion process occurs when the chemical kinetics that are associated with autoignition begin to consume the fuel.

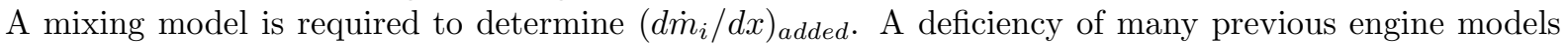
is that they rely on outdated mixing data, and unfortunately the representation of the mixing process is often the weakest link of an entire engine model. To alleviate this potential problem, the present approach is based on modern mixing theory and on mixing data recently obtained with laser imaging diagnostics. First it is assumed that fuel is injected in a sidewall jet that is perpendicular to the supersonic air cross-stream. $\left(d \dot{m}_{i} / d x\right)_{\text {added }}$ is given by:

$$
\left(\frac{d \dot{m}_{F}}{d x}\right)_{\text {added }}=\frac{d}{d x} \int_{A^{\star}} \rho U Y_{F} d A
$$

The integral in Equation 45 is the mass per second of fuel that passes through the area $\mathrm{A}^{*}$. We define $\mathrm{A}^{*}$ to be the grey annular region on each of the vertical planes shown in Fig. 5b. Within this annular region $\mathrm{A}^{*}$ the value of the fuel mass fraction $Y_{F}$ lies between the rich and the lean flammability limits. Thus a "mixed" fluid is defined to be a fluid that has a value of $Y_{F}$ that is in the flammable range.

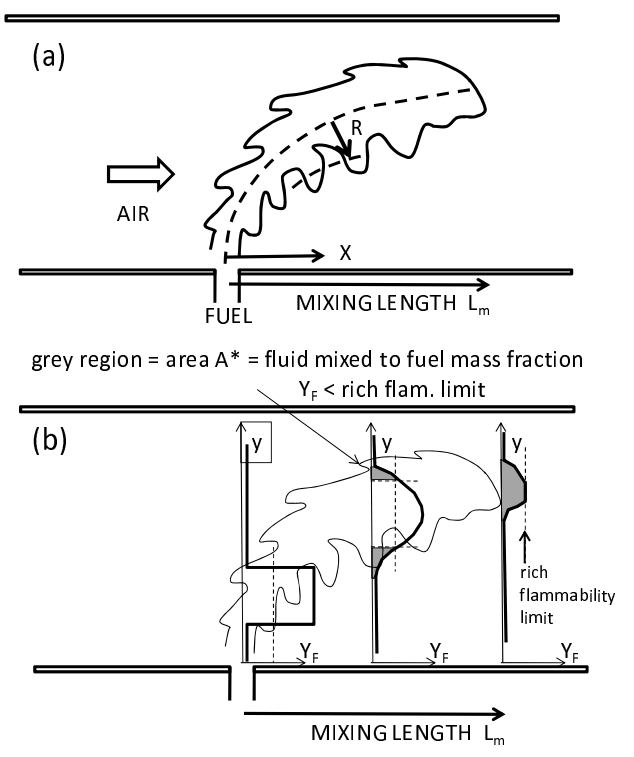

Figure 5. Schematic of the Fuel-Air Mixing Process Considered. Grey region in (b) is $A^{*}$; it represents area through which the fuel mass fraction $Y_{f}$ has been mixed to a value below the rich flammability limit. 
Smith and Mungal [24] have measured the profiles of $Y_{F}$ within a jet injected into a transverse air flow, and Hasselbrink and Mungal [25] showed that there is approximate self-similarity to the scalar and velocity fields. They show that it is possible to simplify Equation 45 to be:

$$
\left(\frac{d \dot{m}_{F}}{d x}\right)_{a d d e d}=\frac{d}{d x}\left(B \rho_{c} U_{c} Y_{F, c} R^{2}\right)
$$

The subscript $c$ refers to properties on the jet centerline, which is the curved dashed line in Figure 5. $R(x)$ is the radius of the jet, and it is identified in Figure 5. In Reference [24] it is reported that $R$ is equal to $0.10 x$. The quantity $B$ is given by:

$$
B=\int_{r_{1} / R}^{r_{2} / R} \frac{\rho}{\rho_{c}} \frac{U}{U_{c}} \frac{f}{f_{c}} 2 \pi \frac{r}{R} \frac{d r}{R}
$$

The limits $r_{2}$ and $r_{1}$ correspond to locations of the rich and lean flammability limits, respectively. Measurements in References [24,25] show that the jet flow in a transverse air stream is approximately self-similar, so the integrand in Equation 45 is the product of three nearly Gaussian functions of $(r / R)$. Inserting these Gaussian functions into Equation 47 it follows that:

$$
B=f\left(Y_{F 2}, Y_{F 1}, Y_{F, c}\right)
$$

$Y_{F 2}$ and $Y_{F 1}$ are the known fuel mass fractions at the rich and lean flammability limits, respectively. The remaining three unknowns in Equations 47 and 48 now are represented in terms of a single unknown: the mixture fraction along the jet centerline $\left(f_{c}\right)$. Mixture fraction is a conserved scalar and it is defined to be the mass fraction of hydrogen atoms, which may exist within $\mathrm{H}_{2}, \mathrm{H}_{2} \mathrm{O}, \mathrm{OH}$ or other molecules [26]. The gas density and fuel mass fraction along the jet centerline are given by mixture fraction concepts [26] to be:

$$
\begin{aligned}
\rho_{c} & =\frac{p}{R_{N 2}}\left[\left(T_{A}+\Delta T-T_{F}\right)\left(\frac{1-f_{c}}{1-f_{s}}\right)+T_{F}\right]^{-1} \text { for fuel rich conditions } f_{c}>f_{s} \\
\rho_{c} & =\frac{p}{R_{N 2}}\left[\left(T_{A}+\Delta T \frac{f_{c}}{f_{s}}\right]^{-1} \text { for fuel lean conditions } f_{c}<f_{s}\right. \\
U_{c} & =U_{F} f_{c} \\
U_{F} & =\sqrt{0.8333 \gamma_{F} R_{F} T_{0 F}} \\
\rho_{F} & =0.6339 \frac{p_{0 F}}{R_{F} T_{0 F}} \\
Y_{F, c} & =\frac{f_{c}-f_{s}}{1-f_{s}}
\end{aligned}
$$

The fuel port is choked, so $U_{F}$ is the sonic velocity of the fuel and $\rho_{F}$ is the sonic density. The fuel stagnation pressure $p_{0 F}$ and stagnation temperature $T_{0 F}$ must be specified. $R_{N 2}$ is the gas constant for nitrogen and $U_{F}$ is the fuel jet velocity. $T_{A}$ is the static temperature of air entering the jet, $T_{F}$ is the initial temperature of the fuel, and $\Delta T$ is the temperature increment that would be added to the air temperature by stoichiometric, $100 \%$ completed combustion. $\Delta T$ is $2065 K$ for hydrogen-air reactants and is $1910 K$ for ethylene-air reactants. The stoichiometric mixture fraction $f_{s}$ is 0.029 for hydrogen-air reactants, and is 0.068 for ethylene-air reactants. To close the problem, a measured scaling relation for the centerline mixture fraction $f_{c}$ is required. It is known from dimensional arguments that $f_{c}$ must depend on the parameters $U_{F} / U_{A}, \rho_{F} / \rho_{A}$, and $x / d$, where $U_{A}$ is the air velocity and $d$ is the fuel port diameter. Planar laser induced fluorescence of acetone seeded into a nonreacting jet in a cross flow was used [24,25] to measure the normalized jet fluid concentration $\xi_{c}$ to be:

$$
\xi_{c}=0.85\left(\frac{x}{d}\right)^{-2 / 3}\left(\frac{\rho_{F}}{\rho_{A}}\right)^{1 / 2}\left(\frac{U_{F}}{U_{A}}\right)^{1 / 3}
$$

The relationship between mixture fraction and normalized jet fluid concentration is:

$$
f_{c}=\frac{\xi_{c} M W_{F}}{\xi_{c} M W_{F}+\left(1-\xi_{c}\right) M W_{A}}
$$


where $M W_{F}$ is the molecular weight of the fuel. The above set of algebraic equations (Equations 45-56) provide values of $\left(\left(d \dot{m}_{f} / d x\right)_{\text {added }}\right.$ as a function of $\mathrm{x}$, which is input into Equation 33. In addition, the equations make it possible to compute the mixing distance $L_{m}$, which is the distance between the fuel injector and the location where the fuel-air mixture is mixed to the rich flammability limit. To determine $L_{m}$ Equation 55 is employed, $\xi_{c}$ is set equal to $\xi_{R}$, the fuel mole fraction at the rich flammability limit. Then $x$ is set equal to $L_{m}$. Rearranging the resulting equation yields the following normalized mixing length (i.e., the distance required to mix the fuel to the rich flammability limit on the centerline of a jet in a transverse air flow):

$$
\frac{L_{m}}{d}=\left(\frac{0.85}{\xi_{R}}\right)^{3 / 2}\left(\frac{\rho_{F}}{\rho_{A}}\right)^{3 / 4}\left(\frac{U_{F}}{U_{A}}\right)^{-1 / 2}
$$

This general approach has been verified for subsonic flames [27-30] and by supersonic transverse jet mixing experiments [31-33]. Equation 57 indicates that increasing the air velocity (UA) causes the flame to bend more in the air flow direction, which increases $L_{m}$. Increasing the fuel velocity $U_{F}$ sufficiently will cause the flame in Figure 5 to be nearly vertical, so its length $L_{m}$ in the air flow direction will be small.

\section{Finite-Rate Chemistry of Hydrogen, Ethylene, or Methane Fuels}

After the fuel and air have mixed to the rich flammability limit, autoignition will occur at the temperatures that are associated with scramjet engines. If the finite-rate chemistry is too slow, not all of the fuel will burn, even though it has been molecularly mixed. The finite-rate chemistry continues throughout the exhaust nozzle, where some recombination will occur. The finite-rate chemistry enters the conservation equations due to the volumetric reaction rate $\dot{\omega}_{i}$, which is defined by Equation 36 and appears in Equation 35. To evaluate $\dot{\omega}_{i}$, the reduced chemical mechanism of Zambon and Chelliah [21] was used. It simulates the kinetics for three possible fuels that are burning in air: ethylene $\left(\mathrm{C}_{2} \mathrm{H}_{4}\right)$, hydrogen $\left(\mathrm{H}_{2}\right)$ and methane $\left(\mathrm{CH}_{4}\right)$. It has been validated against experimental data that describes ignition, flame propagation and extinction for a wide range of equivalence ratios, temperatures and pressures. The 18 reactions and 22 species in the kinetics mechanism are listed in Table 1. The chemical mechanism in Table 1 consists of a FORTRAN code that is imbedded within the MATLAB propulsion code.

\begin{tabular}{|c|c|}
\hline \multicolumn{2}{|c|}{18 Chemical Reactions: } \\
\hline I & $\mathrm{C}_{2} \mathrm{H}_{4}+\mathrm{H}=\mathrm{CH}_{3}+\mathrm{CH}_{2}$ \\
\hline II & $C_{3} H_{5}+H_{2}=C_{3} H_{6}+H$ \\
\hline III & $C_{3} H_{4}+C_{3}=C_{3} H_{6}+H$ \\
\hline IV & $\mathrm{C}_{2} \mathrm{H}_{3}+\mathrm{H}_{2}=\mathrm{CH}_{3}+\mathrm{CH}_{2}$ \\
\hline $\mathrm{V}$ & $C_{2} H_{6}=2 C_{3}$ \\
\hline VI & $\mathrm{CH}_{4}=\mathrm{CH}_{3}+\mathrm{H}$ \\
\hline VII & $\mathrm{C}_{2} \mathrm{H}_{2}+\mathrm{H}_{2}=2 \mathrm{CH}_{2}$ \\
\hline VIII & $\mathrm{CH}_{3}=\mathrm{CH}_{2}+\mathrm{H}$ \\
\hline IX & $\mathrm{CH}_{2} \mathrm{O}+\mathrm{H}_{2}=\mathrm{CH}_{2}+\mathrm{CO}$ \\
\hline $\mathrm{X}$ & $\mathrm{CH}_{2} \mathrm{CO}=\mathrm{CH}_{2}+\mathrm{CO}$ \\
\hline XI & $\mathrm{CO}_{2} \mathrm{H}_{2}+\mathrm{O}=\mathrm{CH}_{2}+2 \mathrm{H}+\mathrm{O}_{2}$ \\
\hline XII & $\mathrm{CO}_{2}=\mathrm{CO}+\mathrm{O}$ \\
\hline XIII & $\mathrm{H}_{2} \mathrm{O}_{2}=2 \mathrm{OH}$ \\
\hline XIV & $\mathrm{HO}_{2}=\mathrm{O}_{2}+\mathrm{H}$ \\
\hline XV & $H_{2}=2 H$ \\
\hline XVI & $\mathrm{H}_{2} \mathrm{O}+\mathrm{H}=\mathrm{H}_{2}+\mathrm{OH}$ \\
\hline XVII & $\mathrm{H}+\mathrm{OH}=\mathrm{H}_{2}+\mathrm{O}$ \\
\hline XVIII & $\mathrm{O}+\mathrm{OH}=\mathrm{O}_{2}+\mathrm{H}$ \\
\hline
\end{tabular}




$\begin{array}{llll}\frac{22 \text { Species: }}{\mathrm{C}_{3} \mathrm{H}_{5},} & \mathrm{C}_{3} \mathrm{H}_{6}, & \mathrm{C}_{2} \mathrm{H}_{2}, & \mathrm{C}_{2} \mathrm{H}_{3}, \\ \mathrm{C}_{2} \mathrm{H}_{4}, & \mathrm{C}_{2} \mathrm{H}_{6}, & \mathrm{CO}, & \mathrm{CO}_{2}, \\ \mathrm{CH}_{2}, & \mathrm{CH}_{3}, & \mathrm{CH}_{4}, & \mathrm{CH}_{2} \mathrm{O}, \\ \mathrm{CH}_{2} \mathrm{CO}, & \mathrm{CH}_{3} \mathrm{O}, & \mathrm{H}_{2}, & \mathrm{H}_{2} \mathrm{O}, \\ \mathrm{H}, & \mathrm{HO}_{2}, & \mathrm{H}_{2} \mathrm{O}_{2}, & \mathrm{O}_{2}, \\ \mathrm{O}, & \mathrm{OH} & & \end{array}$

The flow equations ( 29-36) are solved by using the built-in integration capacity of MATLAB. For computer implementation, the equations are combined by using elimination of variables, so that each flow quantity $\left(p, T, \rho, \overline{M W}, Y_{i}\right.$, etc.) can be found using an explicit equation, rather than a matrix inversion, which could be time-consuming in some cases. The combustor entrance conditions $\left(U, T, p\right.$, and $\left.Y_{i}\right)$ are computed from the flight conditions and the bow shock/inlet relations. The mass added profile, is determined from the mixing analysis, and the area profile $\mathrm{A}(\mathrm{x})$ is given. This results in a set of equations in which all quantities can be determined if the equations are solved in order. The differential equations are solved using the MATLAB ode23tb algorithm. This solver is chosen because it had the best performance (measured in running time) compared to the other available solvers, and because it has the option of preventing the integrands from taking negative values, which is a realistic requirement for this particular problem. It was necessary to choose a solver capable of efficiently handling stiff equations, since there can be large differences in the rates of change of the combustion reaction processes compared to that of state variables.

The 22 species considered in the finite rate reaction mechanism are listed in Table 1; they are typical combustion products. The thermodynamic properties of these 22 species are tabulated in CHEMKIN. ${ }^{34}$ For example, the heat capacity of each of the 22 species is represented as a polynomial function of gas temperature, and the coefficients of each term is stored in the CHEMKIN database. Also stored is the enthalpy of formation of each species, which is used to compute the heat released by combustion and the enthalpy recovered during recombination. The chemical reaction rates are determined using the method of Zambon and Chelliah [21] in a separate FORTRAN code, which interfaces with MATLAB as a MEX file. The chemical kinetics subroutine takes the input values of the concentrations of species and outputs a rate of change of each concentration, which is transferred back to the MATLAB code.

The isolator section and the combustor-isolator interaction are simulated using an analysis that is described in Ref [5] and will not be repeated here. The analysis also accounts for dissociation losses across shock waves in the inlet and isolator. It accounts for real gas changes to the heat capacity. It assumes that the chemical processes associated with $\mathrm{N}_{2}$ and $\mathrm{O}_{2}$ dissociation are so fast that chemical equilibrium is achieved rapidly. The subroutine handles both oblique and normal shocks; only the latter will be described here for simplicity. Anderson ${ }^{35}$ writes the following conservation equations across a normal shock:

$$
\begin{aligned}
\rho_{2} U_{2} & =\rho_{1} U_{1} \\
p_{2}+\rho_{2} U_{2}^{2} & =p_{1}+\rho_{1} U_{1}^{2} \\
h_{2}+\frac{1}{2} U_{2}^{2} & =h_{1}+\frac{1}{2} U_{1}^{2} \\
p_{2} & =\frac{\rho_{2} R_{u} T_{2}}{M W_{2}}
\end{aligned}
$$

Real gas effects are considered by expressing the enthalpy/mass in terms of the contributions from each species:

$$
h_{2}=\sum_{i} Y_{i} h_{i}
$$

The enthalpy/mass for each species is composed of its heat of formation and its sensible enthalpy:

$$
h_{i}=h_{f, i}^{0}+\int_{298 K}^{T} c_{p, i} d T
$$

Heat capacity $c_{p, i}$ is expressed as a polynomial function of the gas temperature using the valued in the CHEMKIN code, and the mass fraction is related to mole fraction by: 


$$
Y_{i}=\sum_{i} X_{i} M W_{i}
$$

The molecular weight of the mixture downstream of the shock is:

$$
M W_{2}=\sum_{i} X_{i} M W_{i}
$$

The mole fractions $\left(X_{i}\right)$ of $\mathrm{O}_{2}, \mathrm{O}, \mathrm{N}_{2}, \mathrm{~N}$ and $\mathrm{NO}$ are related to each other by the Law of Mass Action for a system in chemical equilibrium. For example, for the reaction $O \rightarrow \frac{1}{2} O_{2}$ the equilibrium constant $K_{p}$ relates $X_{\mathrm{O}_{2}}$ to $X_{O}$ in the following way:

$$
K_{p, 1}=\frac{x_{O_{2}}^{1 / 2}}{x_{O}}\left(\frac{p_{2}}{p_{\text {ref }}}\right)^{-1 / 2}
$$

Additional equilibrium relations are written to relate the mole fractions of $N, N_{2}$ and $N O$. Equations 5867 are solved using the algorithm suggested by Anderson. ${ }^{36}$

\section{Results of the New Propulsion Model}

Figure 6 shows some results of the model. The geometry is that of a constant area combustor that is $3 \mathrm{~m}$ long, followed by a nozzle that is $10 \mathrm{~m}$ long. The nozzle exit area is 3.1 times the combustor area. The combustor inlet Mach number is 3.0 and $T_{03}$ is $3200 \mathrm{~K}$. Three different equivalence ratios were chosen to be $0.2,0.4,0.6$. Figure 6 displays the computed mass fractions of $\mathrm{H}_{2} \mathrm{O}, \mathrm{H}_{2}$ and $\mathrm{O}_{2}$. The $\mathrm{H}_{2} \mathrm{O}$ mass fraction rises rapidly at $\mathrm{x}=0$ where the hydrogen is injected. The rate of rise of $\mathrm{H} 2 \mathrm{O}$ depends on both the fuel-air mixing rate and the chemical kinetics. There is a flat region to the $\mathrm{H}_{2} \mathrm{O}$ curves because it is believed that the fuel has been fully consumed. Later in the nozzle $(3 \mathrm{~m}<\mathrm{x}<13 \mathrm{~m})$ it is noted that $\mathrm{H} 2 \mathrm{O}$ rises again, due to the recombination of $\mathrm{OH}$ and $\mathrm{H}$ to $\mathrm{H} 2 \mathrm{O}$. For all three equivalence ratios the mixing distances $\left(L_{m}\right)$ were set to be equal, by adjusting the stagnation pressure of the fuel.
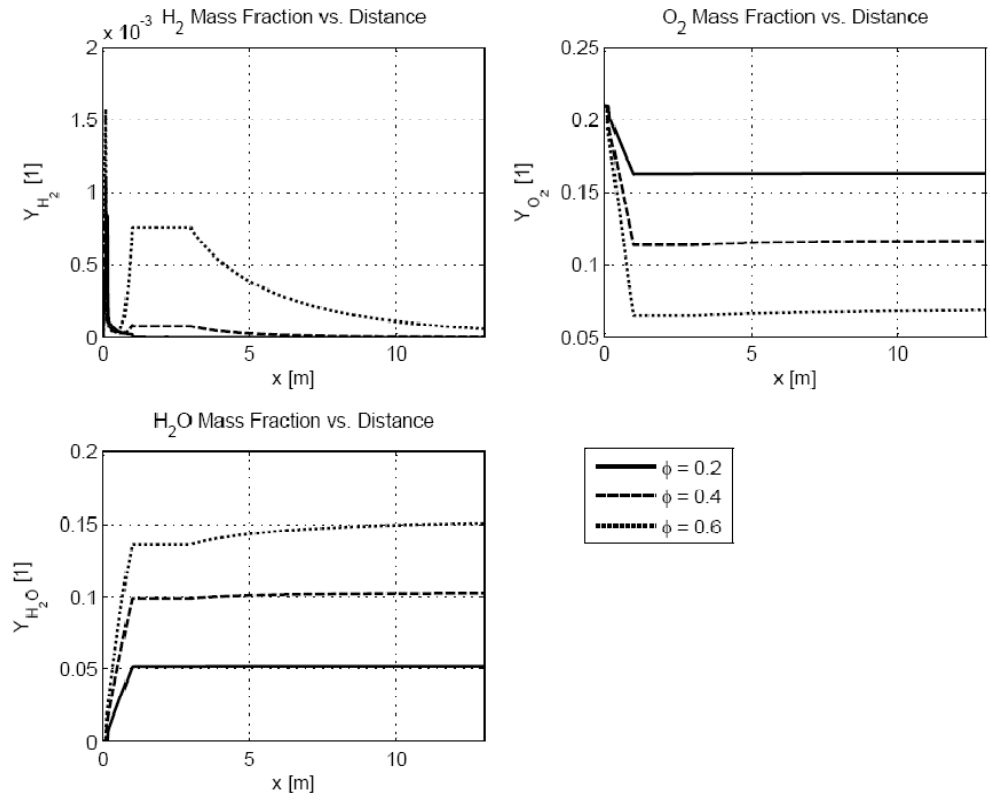

Figure 6. Some Results of the Model: Mass Fraction of H2O, H2 and O2 in the Combustor and Nozzle Sections for the Late Scram Mode (no PCST). Constant area combustor is $3 \mathrm{~m}$ long; the nozzle is $10 \mathrm{~m}$ long. Nozzle exit area is 3.1 times the combustor area. Combustor inlet Mach number $=3.0, T_{03}=3200 \mathrm{~K}$. Hydrogen fuel injected through $1 \mathrm{~cm}$ diameter ports at three equivalence ratios $(\phi)$ of $0.2,0.4,0.6$. Note that recombination continues into the nozzle $(3 \mathrm{~m}<\mathrm{x}<13 \mathrm{~m})$. The chemical kinetic mechanism is that of Zambon and Chelliah [21] 
In Figure 7 the profiles of Mach number indicate that the flow remains supersonic everywhere. For the largest equivalence ratio considered (0.4) the heat additions drives the Mach number down to 1.4. The static temperature rises to as large as $3000 \mathrm{~K}$, but this is considerably less than (and more realistic than) what would be computed if real gas effects and dissociation were neglected. Note that the stagnation temperature profile in Figure 7 indicates that a significant rise in $T_{0}$ occurs in the nozzle. Since there was no $T_{0}$ rise in the region from 2 to $3 \mathrm{~m}$, it is concluded that all of the fuel was consumed in the combustor and the $T_{0}$ rise in the nozzle is entirely due to recombination reactions. Detailed plots such as Figures 6 and 7 are useful to engine designers for a number of reasons. If the static pressure in the combustor becomes too low, the rate of chemical kinetics will drop rapidly and the reaction can extinguish. If a slower burning fuel such as ethylene or methane is used, the chemical reaction rate also may be insufficient. The above results correspond to the late scram mode. Analysis of the ram mode and the transition to early scram mode will be reported in a future paper.
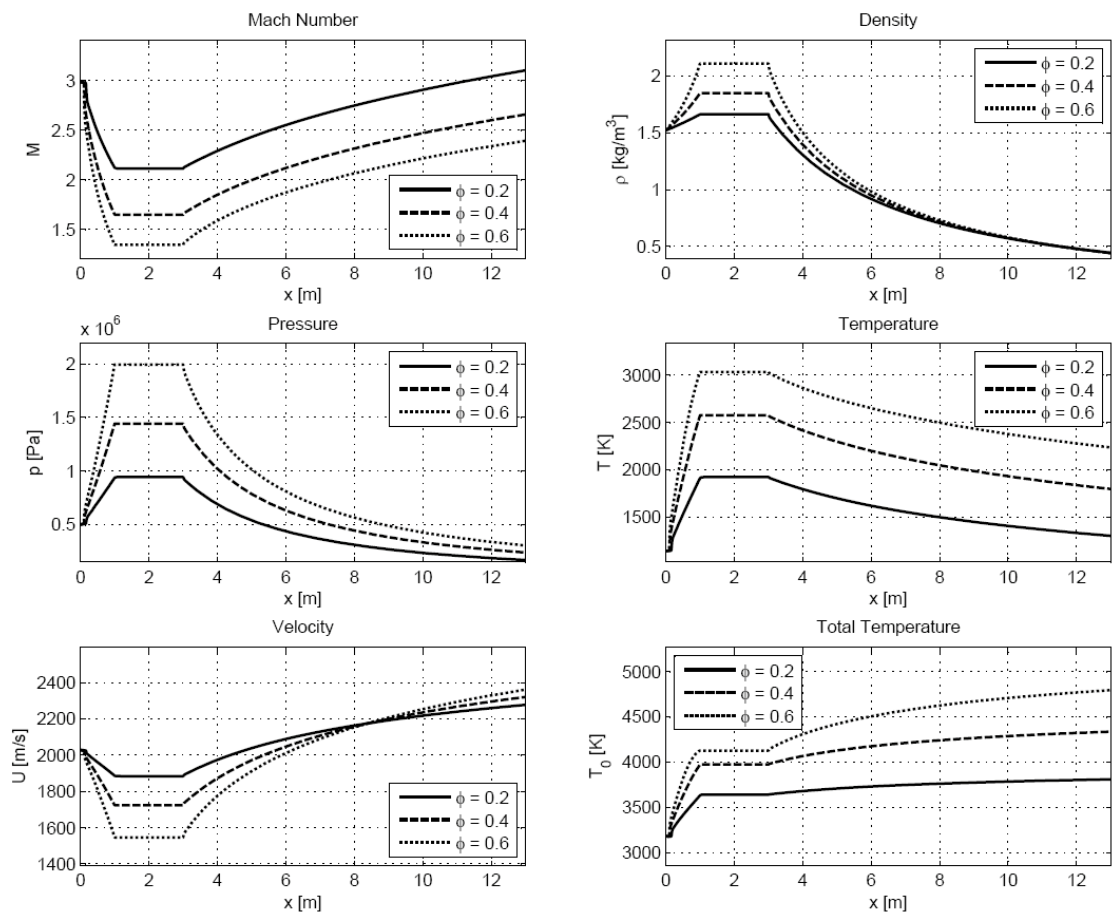

Figure 7. Some Results of the Model: Computed Mach Number, Pressure, Velocity, Density, Static Temperature and Stagnation Temperature in the Combustor and Nozzle Sections. Constant area combustor is $3 \mathrm{~m}$ long; the nozzle is $10 \mathrm{~m}$ long. Nozzle exit area is 3.1 times the combustor area. Combustor inlet Mach number $=3.0$, T03 $=3200 \mathrm{~K}$. Hydrogen fuel injected through $1 \mathrm{~cm}$ diameter ports at three equivalence ratios of 0.2 , 0.4, 0.6.

\section{Analysis of the Hypersonic Vehicle Stability and Control}

The analysis that follows focuses on the open-loop, linearized dynamics of the notional hypersonic vehicle model described above. In particular, we are interested quantifying the effects of the new propulsion system model on the stability and control derivatives, and therefore, the location of the poles of the linearized system. By characterizing these effects on the linear model, we can assess the uncertainty in the system resulting from neglecting certain physical phenomenon in the engine model.

For this analysis, the vehicle was trimmed in steady, level flight at an altitude of 85,000 ft and Mach 8.0 (which corresponds to a dynamic pressure of approximately $2000 \mathrm{psf}$ ). The aircraft was then linearized about the trim condition in order to obtain the open-loop poles and transmission zeros of the linear system. Transmission zeros that are shown are for the input $u=\left[\delta_{e} \delta_{T}\right]^{T}$ and the output $y=\left[v_{t} \gamma\right]^{T}$. The reason for choosing flight path angle $\gamma$ instead of pitch angle $\theta$ as a controlled variable is due to path-attitude 
decoupling. The location of the $T_{\theta_{2}}$ zero in the elevator-to-pitch angle transfer function is located such that there is a significant lag between the pitch attitude and the flight path angle, precluding the use of pitch angle as means to control the flight path angle. However, selecting this input-output pair means that we are controlling a non-minimum phase system. Because this hypersonic vehicle model is open-loop unstable, the location of the transmission zeros relative to the imaginary axis imposes practical limitations on the bandwidth, and thus speed-of-response, that can be achieved for the pitch dynamics. However, the use of a proxy flight path angle can be used to render the system minimum phase and to provide for the desired bandwidth, but that is beyond the scope of this paper.

The linearized dynamics of the vehicle with the two propulsion systems are shown in Figure 8. It is readily apparent that there is a significant shift in the real zero positions. The zero frequencies decrease approximately $1.25 \mathrm{rad} / \mathrm{s}$ when the more complex propulsion system is used in place of the older, more simple model. The effect on the short-period poles is not as significant, as the frequency decreases by about 0.35 $\mathrm{rad} / \mathrm{s}$. The pole and zero migration of the short period poles and the transmission zeros due to the propulsion system model being used can be quantified by looking at the thrust sensitivities and the classical, analytical expressions for the short period poles, and the pair of real zeros of the elevator to flight path angle transfer function. The latter has been shown to be a good approximation to the transmission zeros of the square linear time-invariant system as described above.

The classical, linear approximation for the short-period frequency is written as ${ }^{37}$

$$
\omega_{s p}=\sqrt{M_{q} Z_{\alpha} / V_{t_{0}}-M_{\alpha}}
$$

However, the term $M_{q} Z_{\alpha} / V_{t_{0}}$ in Equation 68 can be neglected for a hypersonic vehicle due to the relative lack of pitch damping and the high velocity of the vehicle. Thus the approximation for the short period frequency becomes:

$$
\omega_{s p} \approx \sqrt{-M_{\alpha}}
$$

The pitching moment for the vehicle is written as the sum of the aerodynamic pitching moment, $M_{\text {aero }}$ and that due to the thrust, $M_{\text {thrust }}$, where $M_{\text {thrust }}=z_{T} T, T$ is the thrust and $z_{T}$ is its offset from the center-ofgravity of the vehicle. Taking the partial derivatives of the pitching moment with respect to angle-of-attack, $\alpha$, we get

$$
\frac{d M}{d \alpha}=\frac{d M_{a e r o}}{d \alpha}+z_{T} \frac{d T}{d \alpha}
$$

Then we can write the pitch stiffness, $M_{\alpha}$ as

$$
M_{\alpha}=\frac{1}{I_{y y}}\left(\frac{d M_{\text {aero }}}{d \alpha}+z_{T} \frac{d T}{d \alpha}\right)
$$

The thrust sensitivity to angle-of-attack for the two propulsion models is shown in Figure 9. In this case, there is a significant difference in the slopes of the two sensitivities for the two models. From Figure 9, the average thrust sensitivity for the original propulsion system model is approximately $-1500 \mathrm{lb} / \mathrm{deg}$ over the range of angle-of-attack that is considered, while the thrust sensitivity for the newer, high fidelity model is approximately $-4500 \mathrm{lb} / \mathrm{deg}$ over the range (neglecting the large spike and the noise, which are attributed to numerical sensitivity resulting from the more complex flow physics.) This change to a more negative slope stabilizes the short-period poles since the thrust vector is located below the center-of-gravity. The difference in the two sensitivities has quantifiable effect in shifting the short period poles due to the ratio of the thrust moment arm, $z_{T}$, to the pitch moment-of-inertia, $I_{y y}$, which is on the order of $3.5 \times 10^{-5}$, but is not the dominant effect. However, it appears that the pitch stiffness due to the aerodynamics (inclusive of the aft-body flow field that is depended upon the nozzle flow exit conditions) is the more dominant of the two effects. One reason is because the new engine model will have a plume pressure different from the original model due to the effect of a variable specific heat. The difference in the trim angle-of-attack and control inputs between the two models is also significant. For example, the trim angle-of-attack and elevator deflection for the original propulsion model are $1.97 \mathrm{deg}$ and $0.48 \mathrm{deg}$ respectively. The model with the new propulsion system model trims at an angle-of-attack of 0.92 deg with an elevator deflection of 6.75 deg. Furthermore, the equivalence ratio is 0.43 for the old model and 0.51 for the new, which indicates different engine exit flow conditions, which will alter the aftbody pressure distribution. Thus, the pitch stiffness moves from $M_{\alpha}=22.671 / \mathrm{s}^{2}$ in the original model to $M_{\alpha}=16.331 / \mathrm{s}^{2}$ in the new model. 
In the numerator of the elevator to flight-path angle transfer function, the zero frequencies $1 / T_{h_{2,3}}$ are approximated by ${ }^{37}$

$$
\frac{1}{T_{h_{2,3}}}= \pm \sqrt{M_{\alpha}-\frac{M_{\delta_{e}}}{Z_{\delta_{e}}} Z_{\alpha}}
$$

It has been shown ${ }^{38}$ that this particular pair of zeros is a good approximation to the transmission zeros of the system with inputs $\delta_{e}$ and $\phi$ and outputs $v_{T}$ and $\gamma$. The added complication here is the ratio $Z_{\delta_{e}} / M_{\delta_{e}}$, which is known as the instantaneous center-of-rotation. This ratio is independent of the throttle setting, but is dependent on the angle-of-attack, Mach number, and the trim elevator position. For the two cases, the instantaneous center-of-rotation moves from $14.03 \mathrm{ft}$ with the original model to $14.3 \mathrm{ft}$ for the new model, thus the reciprocals can assumed to be constant with a value of approximately 0.07 . When the new propulsion system model is incorporated, we observed a change in the derivative $Z_{\alpha}$. If one considers the equation for $\dot{\alpha}$ :

$$
V_{t} \dot{\alpha}=\frac{-T \sin \alpha-L}{m}+V_{t} Q+g \cos \gamma
$$

and calculates the partial derivatives of the right hand side of Equation 73 with respect to $\alpha$ and evaluates at the steady, level flight trim condition $\left(T_{0}, L_{0}, \alpha_{0}, \gamma_{0}=Q_{0}=0\right)$, thus giving

$$
V_{t_{0}} \frac{\partial \dot{\alpha}}{\partial \alpha}=\frac{1}{m}\left(-\frac{\partial L}{\partial \alpha}-\frac{\partial T}{\partial \alpha} \sin \alpha_{0}-T_{0} \cos \alpha_{0}\right)
$$

However, at the trim condition, we also have $T_{0} \cos \alpha_{0}=D_{0}$ in order to satisfy $\dot{V}_{t} \equiv 0$ at $\gamma \equiv 0$. Substituting this into Equation 74 gives the definition of $Z_{\alpha}$ as

$$
Z_{\alpha} \triangleq-\frac{1}{m}\left(\frac{\partial L}{\partial \alpha}+\frac{\partial T}{\partial \alpha}+D_{0}\right)
$$

The effect of the new propulsion model was to move $Z_{\alpha}$ from $-651.77 \mathrm{ft} / \mathrm{s}^{2}$ to $-425.18 \mathrm{ft} / \mathrm{s}^{2}$. Recall that $\partial L / \partial \alpha>0$. Since $\partial T / \partial \alpha<0$, the change in $Z_{\alpha}$ is in part attributed to the fact that the new propulsion model has a much more significant thrust sensitivity as a function of angle-of-attack. However, what hasn't been quantified is the differences in the aft body pressure distributions due to being at different operating conditions, which will affect the lift curve slope of the vehicle. Thus with a reduction both the $Z_{\alpha}$ and $M_{\alpha}$ derivatives when the improved propulsion model is incorporated, it is no surprise that there is a reduction in the frequencies of the $T_{h 2}$ and $T_{h 3}$ zeros.

If we refer to Figure 10, we see a change in the location of the poles associated with the phugoid mode. Here, we consider a different approach to analysis of the phugoid, as we will concentrate on the states $v_{T}$, $\theta$, and $h$. The reason for this is that an analysis of the modal sensitivity of the low frequency, complexconjugate poles and the low-frequency real poles indicates that this is a non-traditional phugoid in the sense that $v_{t}$ and $\theta$ are not the dominant states as in the classical phugoid mode. Instead, the dominant states in the complex-conjugate pair are $\theta$ and $h$ with near equal influence, and to a lessor degree, $\alpha$. The amount of participation of $\alpha$ in the complex-conjugate pair is dependent upon the propulsion model, and becomes more significant when the improved propulsion model is used. Using the three states, $v_{t}, \theta$, and $h$, an approximate characteristic equation for the phugoid mode can be found to be:

$$
p(s)=s^{3}+\left(\frac{M_{v} X_{\alpha}}{M_{\alpha}}-X_{v}\right) s^{2}+\left[Z_{h}+\frac{M_{v}}{M_{\alpha}}\left(V_{t_{0}} X_{h}+\frac{g Z_{\alpha}}{V_{t_{0}}}\right)\right] s+\frac{M_{v}}{M_{\alpha}}\left(-X_{h} Z_{\alpha}-g Z_{h}+X_{\alpha} Z_{h}\right)-X_{v} Z_{h}
$$

where it is assumed that $Z_{q}, Z_{\dot{\alpha}}, M_{q}, M_{\dot{\alpha}}, M_{h}$, and $Z_{v}$ are negligible. Furthermore, due to the presence of the velocity derivatives, the thrust sensitivity to Mach number (velocity) will have an effect on these derivatives. From Figure 11, we see an increased thrust sensitivity to Mach across the Mach number range being considered. This accounts for the change in the real pole associated with the phugoid as this is almost entirely dependent upon $X_{v}$ where

$$
X_{v}=\frac{1}{m}\left(\frac{\partial T}{\partial V_{t}} \cos \alpha_{0}-\frac{\partial D}{\partial V_{t}}\right)
$$

Likewise, the thrust sensitivity to speed shows up in the other terms of the characteristic polynomial. 


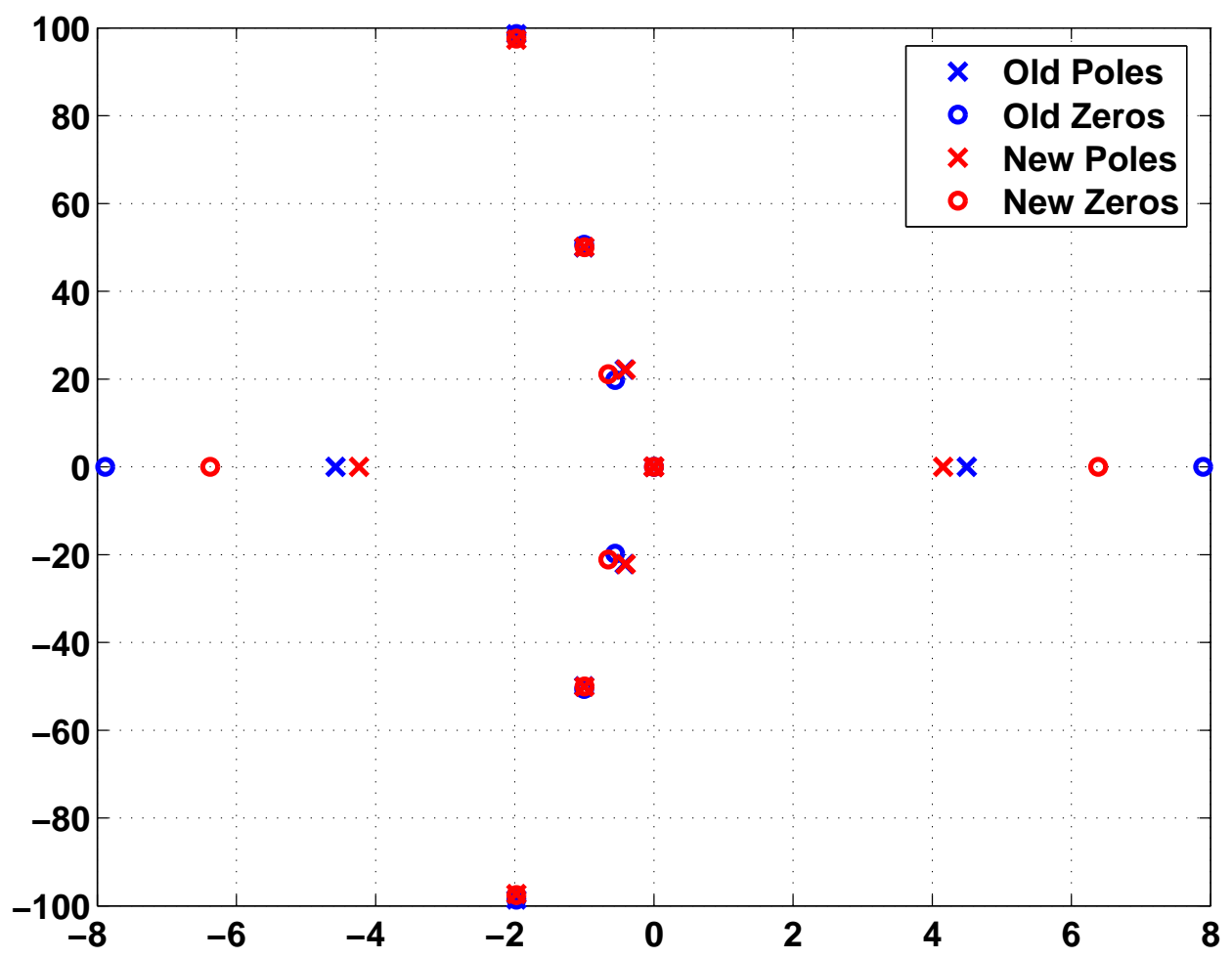

Figure 8. Pole-zero Map of Open-loop Dynamics at Mach 8, 85,0000 ft

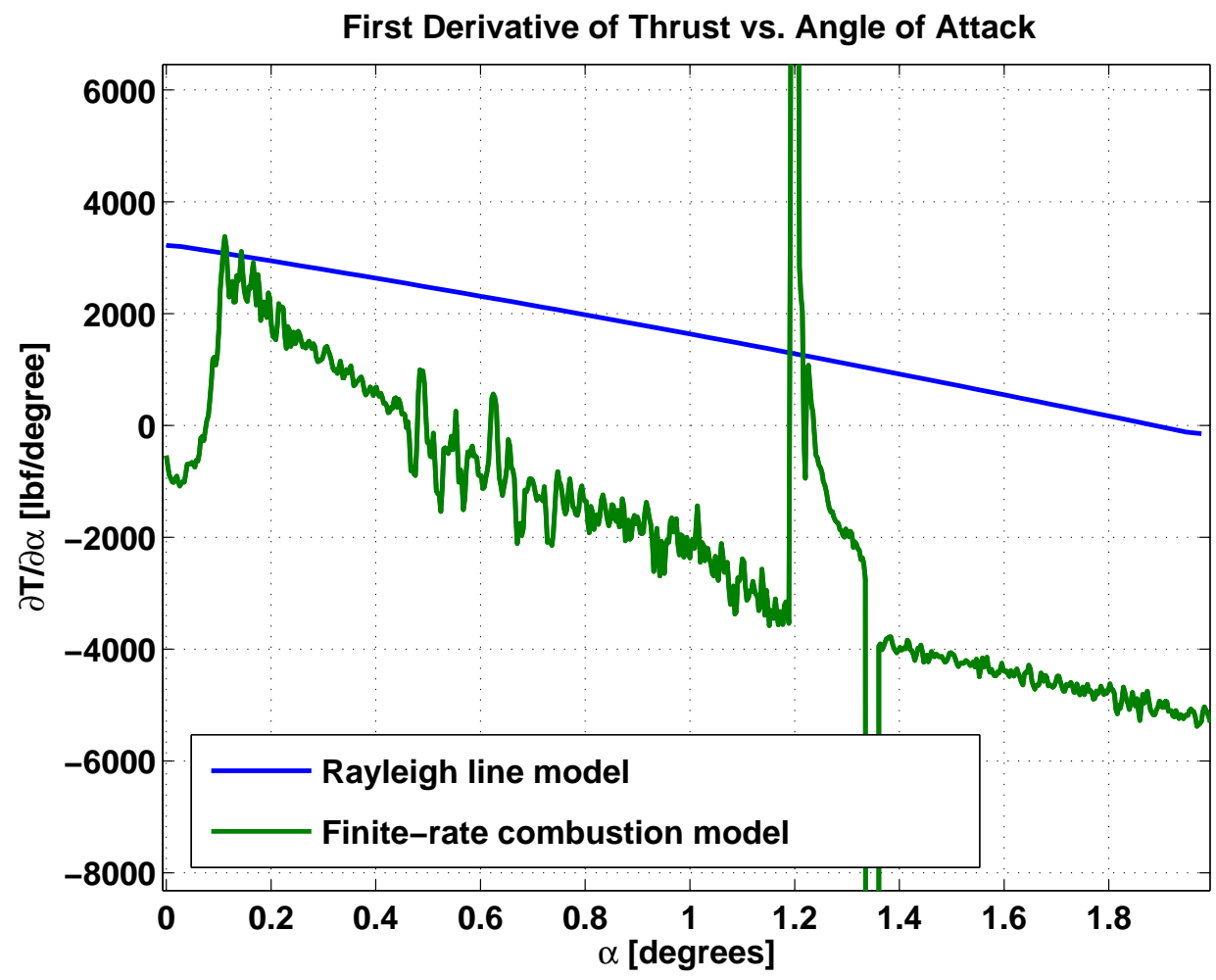

Figure 9. Thrust Sensitivity to Angle-of-Attack at Mach 8, 85,000 ft 


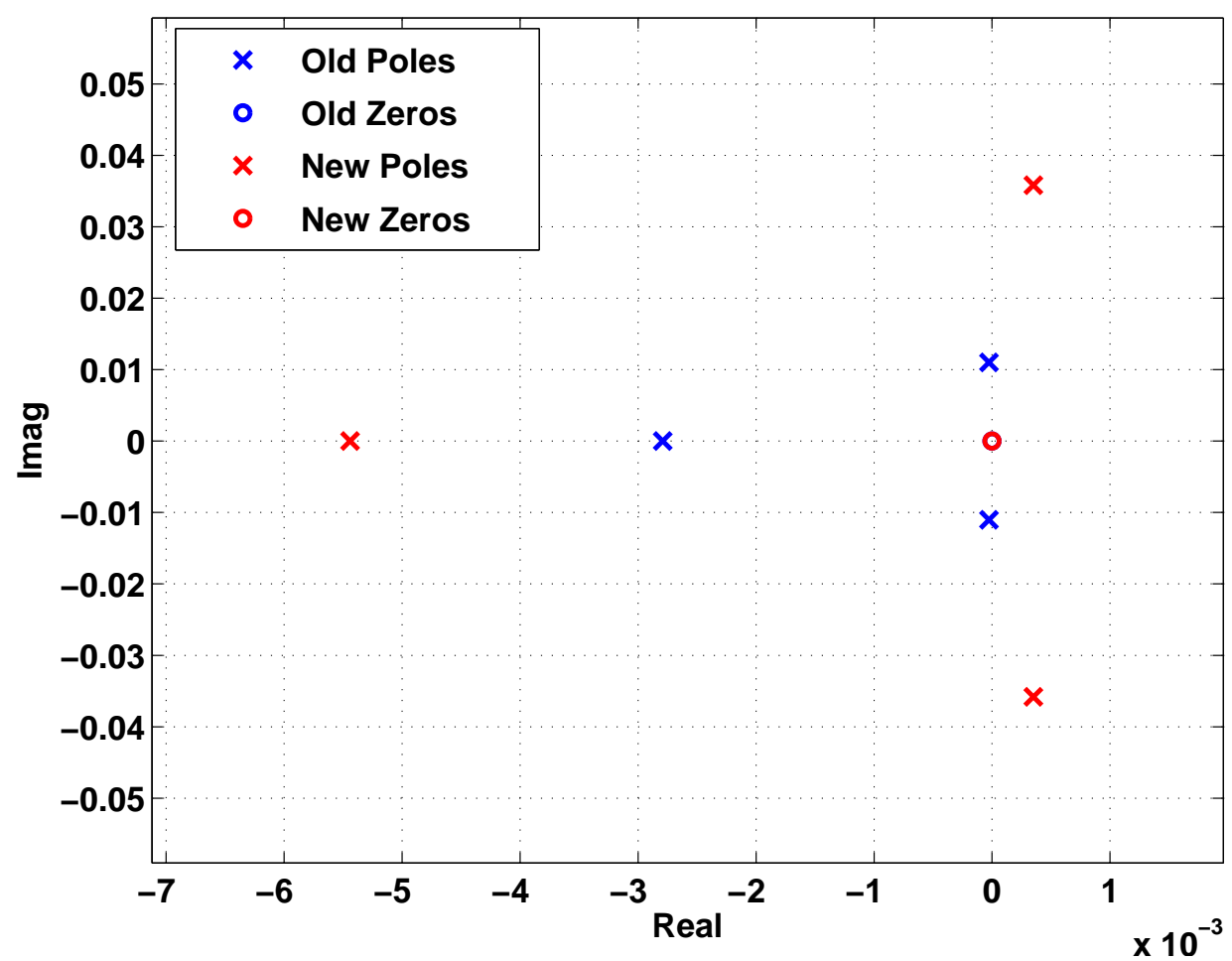

Figure 10. Phugoid Poles for Hypersonic Vehicle Model

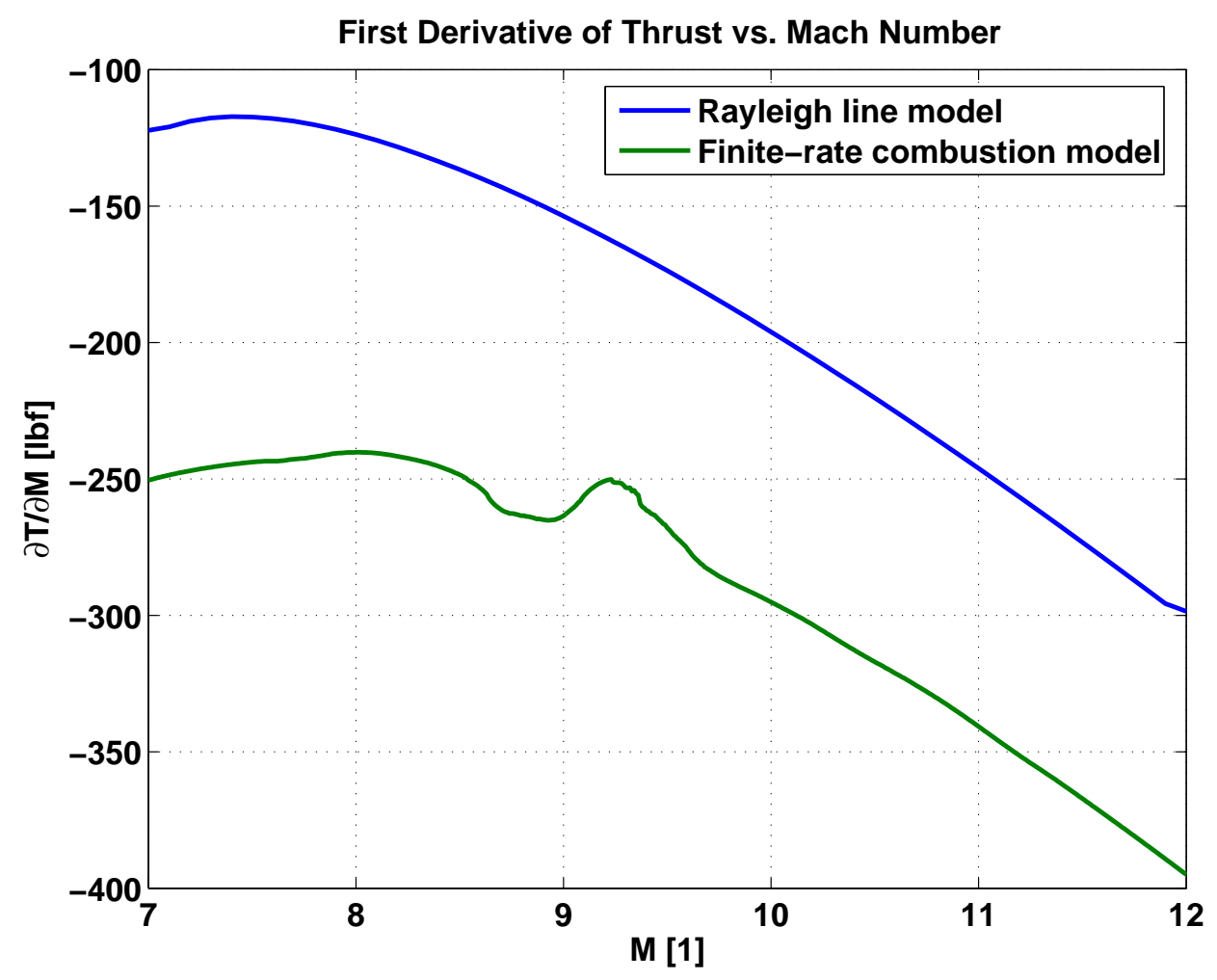

Figure 11. Thrust Sensitivity to Mach Number 
Finally, we want to briefly examine the control derivatives related to the equivalence ratio, specifically $X_{\delta_{T}}, Z_{\delta_{T}}$ and $M_{\delta_{T}}$. In a conventional aircraft, only the derivative $X_{\delta_{T}}$ is important because the thrust's main effect is obviously along the body and stability $x$-axes. However, due to the coupling present between the propulsion system and the aerodynamics for the hypersonic vehicle we are analyzing, the terms $Z_{\delta_{T}}$ and $M_{\delta_{T}}$ are no longer negligible. Table 1 shows the differences in these control derivatives for the two models. The thrust sensitivity with respect to equivalence ratio is given in Figure 12. In each case, the sensitivity is positive, thus indicating that the thrust increases with increasing $\phi$. Note that $\partial T / \partial \phi$ for the finite-rate chemistry model is lower as compared to the Rayleigh flow combustion process. What is also interesting is that the sensitivity of the Rayleigh flow combustion model is strictly increasing with increasing $\phi$, while the sensitivity decreases for the finite-rate chemistry model (for the most part.) These differences can be attributed to the effects of the chemistry and the changes in specific heat that occur due to the inclusion of the combustion chemistry into the model.

\begin{tabular}{lccc}
\hline \hline & $X_{\delta_{T}}$ & $M_{\delta_{T}}$ & $Z_{\delta_{T}}$ \\
\hline Orig. Model & 35.65 & 0.2156 & -8.834 \\
New Model & 41.24 & 0.5570 & -2.471 \\
\hline \hline
\end{tabular}

Table 1. Throttle Control Derivatives

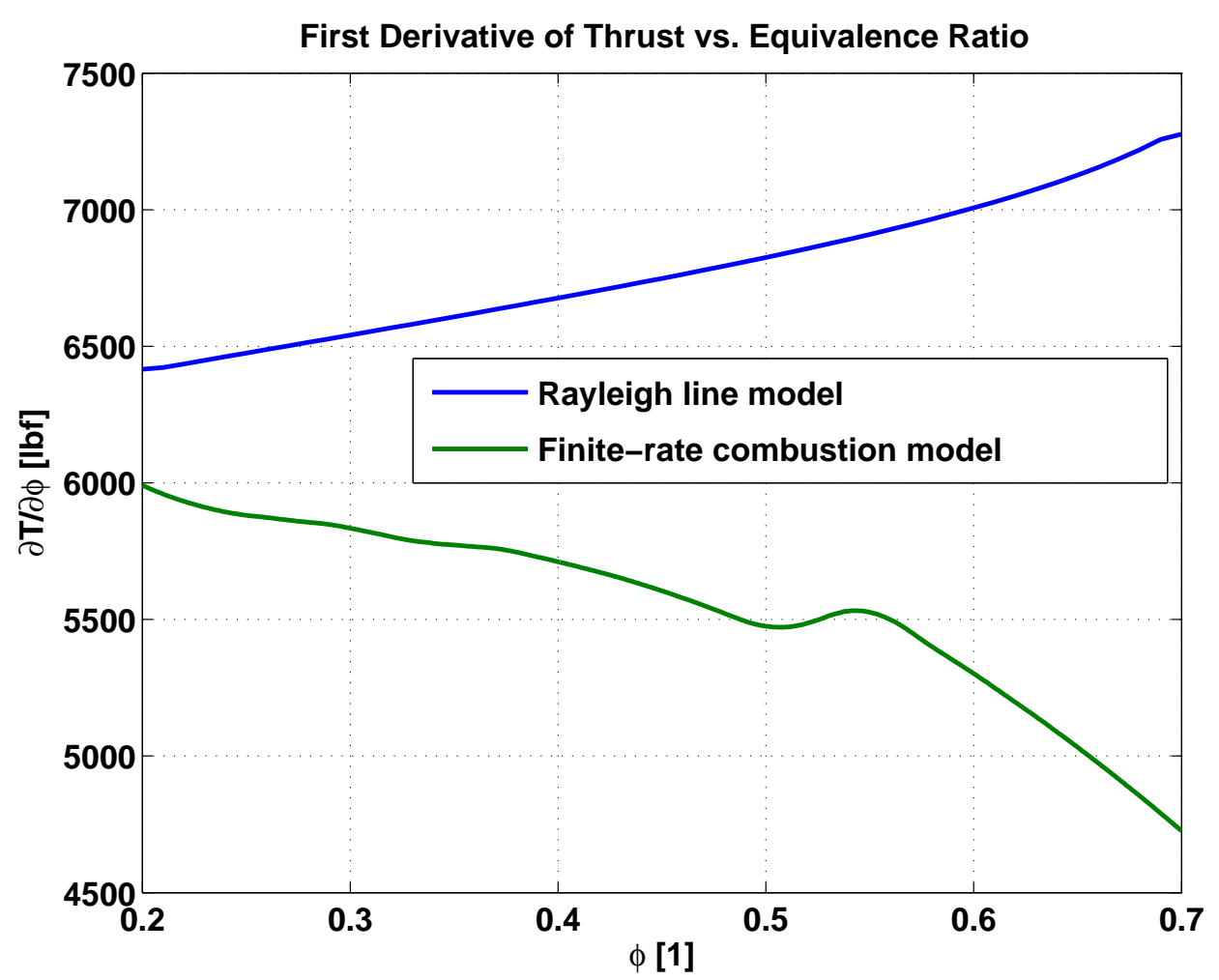

Figure 12. Thrust Sensitivity to Equivalence Ratio

While the above analysis shows an effect on the vehicle dynamics due to the inclusion of a finite-rate chemistry combustion model, it is far from exhaustive or complete. Many issues still remain with respect to the flowpath that was assumed for the model, as the flowpath geometry is not necessarily optimal for this particular vehicle. Furthermore, the simplifying assumptions on the outer mold line may be significant since a preliminarily analysis indicates that there is not enough forebody compression due to the assumption that there is only a single compression ramp, while the $\mathrm{X}-43 \mathrm{~A}$, for example had three angles through which the flow was compressed. Therefore, much future work on the interactions between the airframe and propulsion system is necessary once a relevant vehicle geometry and flowpath are obtained. 


\section{Conclusions}

This paper presents recent additions to a model of a generic hypersonic vehicle and examines their effect on the stability of the vehicle. The propulsion model was updated to consider finite-rate combustion effects, rather than simple heat addition using the Rayleigh-line model. This difference changes the stability of the vehicle and its operating envelope significantly.

The stability effects are mostly due to changes in the trim operating point and changes in the sensitivity to the operating parameters. The trim point changes because thrust is significantly reduced in the new model, which can be considered an indirect result of the updated combustion model. The changes in the sensitivities are direct results, having to do with the finite rate and variable heat capacity processes now included in the flow analysis. The finite rate effects can be seen most clearly in the angle of attack and Mach number sensitivity plots. Changing either of these operating parameters changes the strengths of the shocks and expansions, along with the air mass flow rate into the engine. The difference in air mass flow rate is a first-order effect on the thrust and mostly important because it changes the trim point. The difference in shock and expansion strength changes the pressure and temperature inside the duct, which has a large impact on the thrust sensitivity because both pressure and temperature determine the rate of combustion. For the sensitivities, rate changes are more significant than the changes due to trim condition.

The operating envelope changes because we must now ensure that the flow achieves conditions favorable to combustion. This means that not only must the free stream flow contain a suitable total enthalpy, but also that we must slow the flow enough to convert some of this total enthalpy and increase static temperature and pressure sufficiently. This result will be explored further in a later paper.

The overall effect of the improved combustion model on the flight dynamics of the hypersonic vehicle was to move the short-period poles and the unstable transmission zeros closer to the imaginary axis, showing lighter damping for these modes.

\section{Acknowledgements}

Funds for the Michigan-AFRL Collaborative Center in Control Science (MACCCS) were made available from the Air Force Research Laboratory Air Vehicles Directorate grant number FA 8650-07-2-3744.

\section{References}

\footnotetext{
${ }^{1}$ Bolender, M. A. and Doman, D. B., "Nonlinear Longitudinal Dynamical Model of an Air-Breathing Hypersonic Vehicle," Journal of Spacecraft and Rockets, Vol. 44, No. 2, March/April 2007, pp. 374-387.

${ }^{2}$ Oppenheimer, M. W. and Doman, D. B., "A Hypersonic Vehicle Model Developed with Piston Theory," AIAA 2006-6637.

${ }^{3}$ Oppenheimer, M. W., Doman, D. B., Bolender, M. A., and Skujins, T., "A Flexible Hypersonic Vehicle Model Developed with Piston Theory," AIAA 2007-6396.

${ }^{4}$ Oppenheimer, M. W. and Doman, D. B., "Viscous Effects for A Hypersonic Vehicle Model," In preparation for submittal to the 2008 AIAA Atmospheric Flight Mechanics Conference.

${ }^{5}$ Torrez, S. M., Scholten, N., Micka, D., Driscoll, J. F., Bolender, M., Doman, D., and Oppenheimer, M. W., "A Scramjet Engine Model Including Effects of Precombustion Shocks and Dissociation," AIAA 2008-4619.

${ }^{6}$ Chavez, F. and Schmidt, D., "Analytical Aeropropulsive/Aeroelastic Hypersonic-Vehicle Model with Dynamic Analysis," Journal of Guidance, Control, and Dynamics, Vol. 17, No. 6, Nov-Dec 1994, pp. 1308- 1319.

${ }^{7}$ Williams, T., Bolender, M. A., Doman, D. B., and Morataya, O., "An Aerothermal Flexible Mode Analysis of a Hypersonic Vehicle," AIAA 2006-6647.

${ }^{8}$ Culler, A., Williams, T., and Bolender, M., "Aerothermal Modeling and Analysis of a Hypersonic Vehicle," AIAA-20076395.

9 "Equations, Tables, and Charts for Compressible Flow," Tech. Rep. NACA-1135, National Advisory Committee for Aeronautics, Ames Aeronautical Laboratory, Moffett Field, CA, 1953.

${ }^{10}$ John, J., Gas Dynamics, chap. 10, Allyn and Bacon, 7 Wells Ave, Newton MA 02159, 1984, pp. 139-150.

${ }^{11}$ Lighthill, M., "Oscillating Airfoils at High Mach Number," Journal of the Aeronautical Sciences, Vol. 20, No. 6, 1953, pp. $402-406$.

${ }^{12}$ Ashley, H. and Zartarian, G., "Piston Theory - A New Aerodynamic Tool for the Aeroelastician," Journal of the Aeronautical Sciences, Vol. 23, No. 12, 1956, pp. 11091118.

${ }^{13}$ Tarpley, C. and Lewis, M., "Stability Derivatives for a Hypersonic Caret-Wing Waverider," Journal of Aircraft, Vol. 32, No. 4, pp. $795-803$.

${ }^{14}$ Anderson, J. D., Hypersonic and High Temperature Gas Dynamics, American Institute of Aeronautics and Astronautics, 1989.

${ }^{15}$ Bolender, M. A. and Doman, D. B., "Modeling Unsteady Heating Effects on the Structural Dynamics of a Hypersonic Vehicle," AIAA 2006-6646.
} 
${ }^{16}$ Shapiro, A. H., Dynamics and Thermodynamics of Compressible Fluid Flow, Ronald Press, NY, 1953.

${ }^{17}$ O'Brien, T. F., Starkey, R. P., and Lewis, M. J., "Quasi-One-Dimensional High-Speed Engine Model with Finite-Rate Chemistry," Journal of Propulsion and Power, Vol. Vol. 17, No. 6, 2001, pp. pp. 1366-1374.

${ }^{18}$ Starkey, R. P., "Off-Design Performance Characterization of a Variable Geometry Scramjet," AIAA 2005-3711.

${ }^{19}$ Birzer, C. and Doolan, C., "Quasi-One-Dimensional Modeling of Hydrogen Fuelled Scramjet Combustors," AIAA 20074314.

${ }^{20}$ Tetlow, M. and Doolan, C., "Comparison of Hydrogen and Hydrocarbon-Fueled Scramjet Engines for Orbital Insertion," Journal of Spacecraft and Rockets, Vol. Vol. 44, No. 2, 2007, pp. pp. 365-372.

${ }^{21}$ Zambon, A. C. and Chelliah, H. K., "Explicit Reduced Reaction Models for Ignition, Flame Propagation, and Extinction of C2H4/CH4/H2 and Air Systems," Combustion and Flame, Vol. Vol. 150, 2007, pp. pp. 71-91.

${ }^{22}$ Heiser, W. H. and Pratt, D. T., Hypersonic Airbreathing Propulsion, AIAA Pub., Washington, DC, 1994.

${ }^{23}$ Heiser, W. and D., P., Hypersonic Airbreathing Propulsion, American Institute of Aeronautics and Astronautics, 370 L'Enfant Promenade, SW,Washington D.C., 20024-2518, 1994, pp. 109-143.

${ }^{24}$ Smith, S. H. and Mungal, M. G., "Mixing, Structure and Scaling of the Jet in Crossflow," Journal of Fluid Mechanics, Vol. Vol. 357, 1998, pp. pp. 83-122.

${ }^{25}$ Hasselbrink, E. F. and Mungal, M. G., "Transverse Jets and Jet Flames: Part 1. Scaling Laws for Strong Transverse Jets," Journal of Fluid Mechanics, Vol. Vol. 443, 2001, pp. pp. 1-25.

${ }^{26}$ Kuo, K. K., Principles of Combustion, Wiley and Sons, NY, 2005.

${ }^{27}$ Broadwell, J. E. and Breidenthan, R. E., "Structure and Mixing of a Transverse Jet in Incompressible Flow," Journal of Fluid Mechanics, Vol. Vol. 148, 1984, pp. pp. 405-412.

${ }^{28}$ Huang, R. F. and Chang, J. M., "The Stability and Visualized Flame and Flow Structures of a Combusting Jet in Cross Flow," Combustion and Flame, Vol. Vol. 98, 1994, pp. pp. 267-278.

${ }^{29}$ Kalghatgi, G. T., "The Visible Shape and Size of a Turbulent Hydrocarbon Jet Diffusion Flame in a Cross-wind," Combustion and Flame, Vol. Vol. 52, 1983, pp. pp. 91-106.

${ }^{30}$ Majeski, A. J., Wilson, D. J., and Kostiuk, L. W., "Predicting the Length of Low-momentum Jet Diffusion Flames in Crossflow," Combustion Science and Technology, Vol. Vol. 176, No. 12, 2004, pp. pp. 2001-2025.

${ }^{31}$ Gruber, M. R., Nejad, A. S., Chen, T. S., and Dutton, J. C., "Compressibility Effects in Supersonic Transverse Injection Flowfields," Phys. Fluids, Vol. Vol. 9 No. 5, 1997, pp. pp. 1448-1455.

${ }^{32}$ Heister, S. D. and Karagozian, A. R., "Gaseous Jets in Supersonic Crossflow," AIAA Journal, Vol. Vol. 28, 1990, pp. pp. 819-827.

${ }^{33}$ Driscoll, J. F.; Huh, H. Y. Y. and Donbar, J., "Measured Lengths of Supersonic Hydrogen Air Jet Flames Compared to Subsonic Flame Lengths and Analysis," Combustion and Flame, Vol. Vol. 107, 1996, pp. pp. 176-186.

${ }^{34}$ Kee, R. J., Rupley, F. M., Miller, J. A., Coltrin, M. E., Grcar, J. F., and et. al., CHEMKIN Release 4.1, Reaction Design, San Diego, CA, 2006.

${ }^{35}$ Anderson, J. D., Hypersonic and High Temperature Gas Dynamics, McGraw Hill, 1989, p. 16.

${ }^{36}$ Anderson, J. D., Hypersonic and High Temperature Gas Dynamics, American Institute of Aeronautics and Astronautics, 1989.

${ }^{37}$ McRuer, D., Ashkenas, I., and Graham, D., Aircraft Dynamics and Automatic Control, Princeton University Press, 1973, pp. 334-345.

${ }^{38}$ Bolender, M. and Doman, D., "Flight Path Angle Dynamics of Air-Breathing Hypersonic Vehicles," AIAA-2006-6692. 